\title{
Fuzzy-PI Based DVR Setup for Voltage Dip and Voltage Swell Problems with Hardware Comparison
}

\author{
${ }^{1} \mathrm{G}$. Devadasu and ${ }^{2} \mathrm{M}$. Sushama \\ ${ }^{1}$ Department of EEE, CMR College of Engineering and Technology, Hyderabad, India \\ ${ }^{2}$ Department of EEE, JNTUH University Hyderabad, Hyderabad, India
}

\begin{abstract}
Power quality issues have been pulling in the eye of investigates for decade. The nearness of voltage unsettling influences at the purpose of normal coupling brings about glitch of delicate modern instruments which ends up being matrix part disappointments. Although, there are many strategies in practice, the term custom power relates to the utilization of energy hardware controller in an appropriate framework, particularly to manage different power quality issues. Now the custom power devices play a vital role in the field of power quality mitigation. The presence of sensitive loads lead to the power quality issues like sag and swell but it is inevitable. DVR is one of the popular and efficient custom power devices most suitable distribution network to mitigate the voltage dip and swell. Fuzzy based PI control is incorporated in this study. The main salient feature is the use of linguistic variables rather than numerical variables. This control method depends on human capacity to comprehend the frameworks conduct and depends on quality control rules. An experimental investigation on the mitigation of sag and swell by using three phase Dynamic Voltage Restorer (DVR) is proposed in this study. It is observed that the compensating capability of the DVR is somewhat lagged due the finite voltage dip under particular loading. A fuzzy based PI scheme is therefore proposed to improve the voltage compensation. The simulation result is appraised with experimental results and it presented it witnessed the effectiveness of the control strategy.
\end{abstract}

Key words: Power Quality PQ, Point of Common Coupling (PCC), Dynamic Voltage Restorer (DVR), fuzzy logic controller Fuzzy Logic (FL), mitigation, Dynamic Voltage Restorer (DVR)

\section{INTRODUCTION}

Power quality issues are an issue that is winding up progressively vital to power customers at all levels of use. Power quality issues have been pulling in the eye of looks into for decade. Power quality related issues are of most trouble in view of the broad utilization of electronic equipment. The various power quality disturbances which affect the quality of power are listed as voltage drop, voltage swell, voltage flickering long and short duration interruptions, presence of harmonics and unbalanced voltages. In the researcher investigates the design requirement of the DVR scheme for mitigating the power quality issues in power distribution system. The researcher perfomed many case study on the basis of the DVR topology and control schemes (Li et al., 2007) studied the transient responses of the DVR based on this study control schemes are proposed to alleviate the voltage dip and suppress the high frequency oscillation. Mangalanathan (2014) proposed a MOSFET based single phase DVR design for the mitigation of voltage sag and swell. The MOSFET was triggered by the microcontroller based PWM technique. The power quality issues are generated by creating the fault in the system. Roncero-Sanchez et al. (2009), A repetitive controller based on the control system scheme is suggested for Dynamic Voltage Restorer (DVR) to compensate the harmonics, sags in voltage and imbalance voltages. In the researcher addressed the restoration capability of the DVR during the power quality issue occurred in the distribution system. Devadasu and Sushama, (2015) suggested a three phase DVR topology energized by multilevel inverter with five level output. Here, the researcher used the power compensation at minimum level in order to reduce the energy storage requirement of the multilevel DVR. Mostafa et al. proposed a new DVR topology based on H-bridge cascaded multi level inverter. Here, the DVR topology is enhanced by the absence of transformer with energy optimized control scheme. This scheme reduces the ride through capability of the DVR.

Devadasu and Sushama, (2017a-d) Diode clamped multilevel converter IDVR is suggested for the power quality problems like sag swell. In this scheme the load power factor is reduced during sag o swell condition in turn increases the compensation capacity. Moreover, in

Corresponding Author: M. Sushama, Department of EEE, JNTUH University Hyderabad, Hyderabad, India 
this research SVPWM technique is employed in the IDVR scheme to inject the voltage with low THD which avoids the presence of isolation transformer in one side. This study discusses the power quality issues created when the renewable resources integrated with the distribution system. The research also analyzes the different mitigation methodology with custom power devices. In Lachlan et al. discussed the technique of identifying power quality disturbances in terms of time and frequency using the wavelet based on the software analysis. Omar et al. discussed the role of DVR in the low voltage distribution system during power quality disturbances. Here, the DVR employs an advance dq0 control strategy. The simulation result is appraised with the hardware result of the DVR set up. Devadasu and Sushama, (2018), the emphasized the DVR with fuzzy logic control strategy. Fuzzy logic provides an easy way to reach the desire conclusion even though the input is vague and ambiguous (Devadasu and Sushama, 2015; Devadasu and Sushama, 2017a-d).

\section{MATERIALS AND METHODS}

Mitigation of power quality problems: DVR is a static series compensator which is used to remove supply side voltage disturbances and also keeps the load side voltage at a desired magnitude and phase by compensating the voltage sags/swells at PCC (Fig. 1).

Injection/Booster transformer: The injection/booster transformer is used to transfer the energy from primary side to secondary and to reduce the coupling noise. This unit makes the connection between DVR and distribution network through the high voltage winding and injects the compensating voltage generated from the VSC to the supply side.

Harmonic filter: It is used to keep the harmonic voltage generated by the VSC within the admissible level. When large voltage source occurs the storage devices-such as flywheels, batteries will provide the real power compensation.

Voltage source converter: It consists of storage and switching devices. It is used to provide a sinusoidal voltage at any needed magnitude, frequency and phase angle. Here, VSC provide the temporary compensation or part of the voltage which is needed for the compensation.

DC charging circuit: It plays two vital role of charging the energy source after the compensation and maintains the DC link voltage at nominal level.

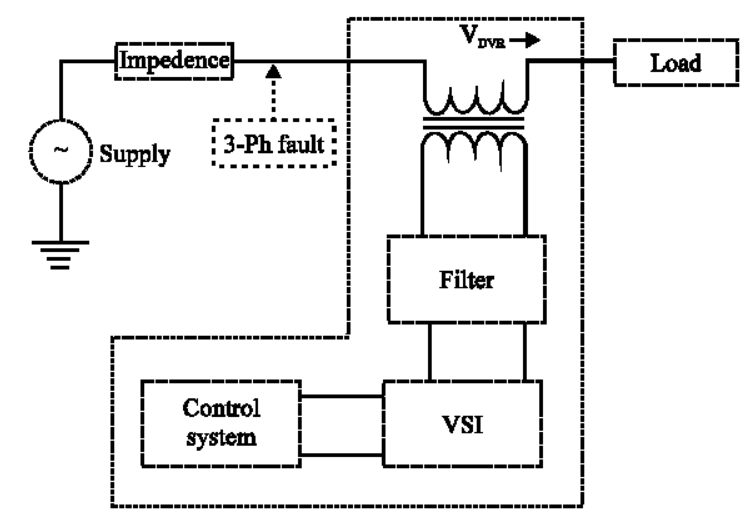

Fig. 1: Schematic diagram of a dynamic voltage restorer

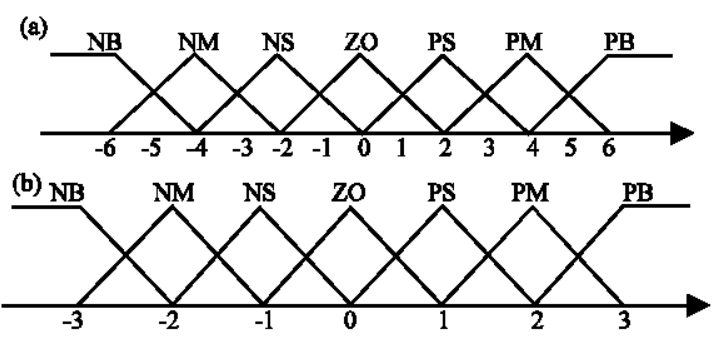

Fig. 2: Membership functions of the fuzzy variable: a) Membership function of $\Delta \mathrm{K}_{\mathrm{p}}$ and $\Delta \mathrm{K}_{\mathrm{i}}$ and $\mathrm{b}$ ) Membership function of $\mathrm{e}(\mathrm{K})$ and $\mathrm{e}_{\mathrm{c}}(\mathrm{K})$

Control and protection: It provides all necessary protection to the DVR by the hardware and programe logic software.

Control scheme of DVR: The control scheme is designed in such a ways to ensure the balance, constant linear nature of the load voltage and current. Also, ensure the zero phase difference between source current and fundamental component of PCC voltage. To do so, the reactive power of the load is met by the DVR.

From the real system the error ' $\mathrm{e}$ ' and change of error ' $e c$ ' are used as numerical variables. The conversion of numerical variables in to linguistic variables is done by adopting the following fuzzy sets: Negative Big (NB), Negative Medium (NM), Negative Small (NS), Zero (ZE), and Positive Small (PS), Positive Medium (PM) and Positive Big (PB). The membership function of the fuzzy sets is chosen in such a way to confirm the robustness and sensitivity of the controller. $\mathrm{e}(\mathrm{K}), \mathrm{e}_{\mathrm{c}}(\mathrm{K}), \Delta \mathrm{K}_{\mathrm{p}}$ and $\Delta \mathrm{K}_{\mathrm{i}}$ in this study are acquired from the ranges of e, $\mathrm{e}_{\mathrm{c}}, \Delta \mathrm{K}_{\mathrm{p}}$ and $\Delta \mathrm{K}_{\mathrm{i}}$ which are obtained from study and experience. And the membership functions are shown in Fig. 2. The important factors considered for designing the control rule base for tuning $\Delta \mathrm{K}_{\mathrm{p}}$ and $\Delta \mathrm{k}_{1}$ : 
- A small change in $\mathrm{K}_{\mathrm{p}}$ is enough for small values of error $|e|$ at the same time for large values of error $|e| a$ large $\Delta \mathrm{K}_{\mathrm{p}}$ is required

- If $\mathrm{e}-\mathrm{e}_{\mathrm{c}}>0$, then $\Delta \mathrm{K}_{\mathrm{p}}$ is large and If $\mathrm{e}-\mathrm{e}_{\mathrm{c}}<0$ then $\Delta \mathrm{K}_{\mathrm{p}}$ is small

- if $|e|$ and $\left|e_{c}\right|$ are large then $\Delta \mathrm{K}_{1}$ is zero

- $\Delta \mathrm{K}_{1}$ is effective when the values of $|\mathrm{e}|$ is small and $\Delta \mathrm{K}_{1}$ is larger when $|\mathrm{e}|$ is smaller which is better to decrease the steady-state error. So, the tuning rules of $\Delta \mathrm{K}_{\mathrm{p}}$ and $\Delta \mathrm{K}_{1}$ can be shown below in Table 1 and 2 .

Constant band width hysteresis control method has high switching frequency which leads to the system loss. For that here the fuzzy controller is used. This controller also I improve the behavior of DVR and also produce the

$\underline{\text { Table 1: The rule for adjusting } \Delta \mathrm{K}_{\mathrm{p}}}$

\begin{tabular}{|c|c|c|c|c|c|c|c|}
\hline \multirow[b]{2}{*}{$\Delta \mathrm{kp}(\mathrm{e})$} & \multicolumn{7}{|l|}{$e_{c}$} \\
\hline & NB & NM & NS & 0 & PS & PM & PB \\
\hline NB & PB & $\mathrm{PB}$ & PB & PM & PM & PS & 0 \\
\hline $\mathrm{NM}$ & PB & PB & PM & PM & PS & 0 & NS \\
\hline NS & PM & PM & PS & PS & 0 & NS & $\mathrm{NM}$ \\
\hline 0 & PM & PS & PS & 0 & NS & $\mathrm{NM}$ & $\mathrm{NM}$ \\
\hline PS & PS & PS & 0 & NS & NS & $\mathrm{NM}$ & $\mathrm{NM}$ \\
\hline PM & PS & 0 & NS & NM & $\mathrm{NM}$ & $\mathrm{NM}$ & NB \\
\hline PB & 0 & NS & NS & $\mathrm{NM}$ & $\mathrm{NM}$ & $\mathrm{NB}$ & $\mathrm{NB}$ \\
\hline
\end{tabular}

Table 2: The rule for adjusting $\Delta \mathrm{K}_{\mathrm{i}}$

\begin{tabular}{|c|c|c|c|c|c|c|c|}
\hline \multirow[b]{2}{*}{$\Delta \mathrm{K}_{\mathrm{i}}(\mathrm{e})$} & \multicolumn{7}{|l|}{$\mathrm{e}_{\mathrm{c}}$} \\
\hline & NB & $\mathrm{NM}$ & NS & 0 & PS & PM & $\mathrm{PB}$ \\
\hline NB & 0 & 0 & NB & NM & $\mathrm{NM}$ & 0 & 0 \\
\hline NM & 0 & 0 & $\mathrm{NM}$ & NM & NS & 0 & 0 \\
\hline NS & 0 & 0 & NS & NS & 0 & 0 & 0 \\
\hline 0 & 0 & 0 & NS & 0 & PS & 0 & 0 \\
\hline PS & 0 & 0 & 0 & PS & PS & 0 & 0 \\
\hline PM & 0 & 0 & PS & PM & PM & 0 & 0 \\
\hline PB & 0 & 0 & PS & PM & $\mathrm{PB}$ & 0 & 0 \\
\hline
\end{tabular}

five level converters output. The one input of the fuzzy controller is difference of injected and reference voltage another input is derivative of error.

The controller directly turns on or turns off the switches based on the voltage condition by considering the difference between converter output voltage and reference voltage and its derivation. In conventional hysteresis voltage control method, switching signals are generated when the error reaches to upper or lower hysteresis band but as shown in Fig. 3 in this proposed method generate the switching signals based on the value of the error and derivation of the error.

The main considerations for the control system of a DVR include detection of sag/swell, voltage reference generation, transient and steady-state control of the injected voltage and protection of the system.

Simulation circuit: Usually, due to switching on and switching off of loads and nonlinear loads power quality problems are occurring. Increase in load creates a sag whereas sudden removal of load creates a swell. At once the sag or swell is occurred at load side, the magnitude of the voltage is compared with the reference signal. The error between these two is given as an input to the PI controller. The PI controller voltage is taken as feedback. The PI controller based on fuzzy is the most frequently used controller in the DVRs. The performance of PI controller under wide range of operating condition is not appreciable. This drawback is overcome by the proposed fuzzy-PI controller. In this control method, PLL tracks the phase angle of all three phases of the network and based on that it generates the reference signal for each phase.

It is because, the phase of the supply voltage prior to the sag is usually chosen and if the PLL reacts swiftly to changes in the phase during sag, the post-sag phase may

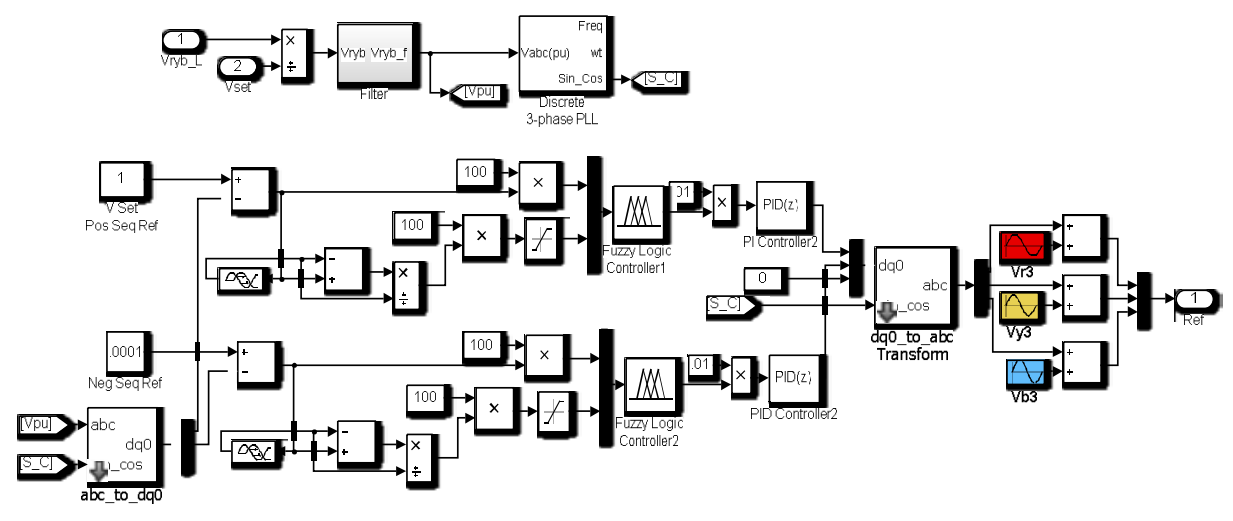

Fig. 3: Control structure of DVR 


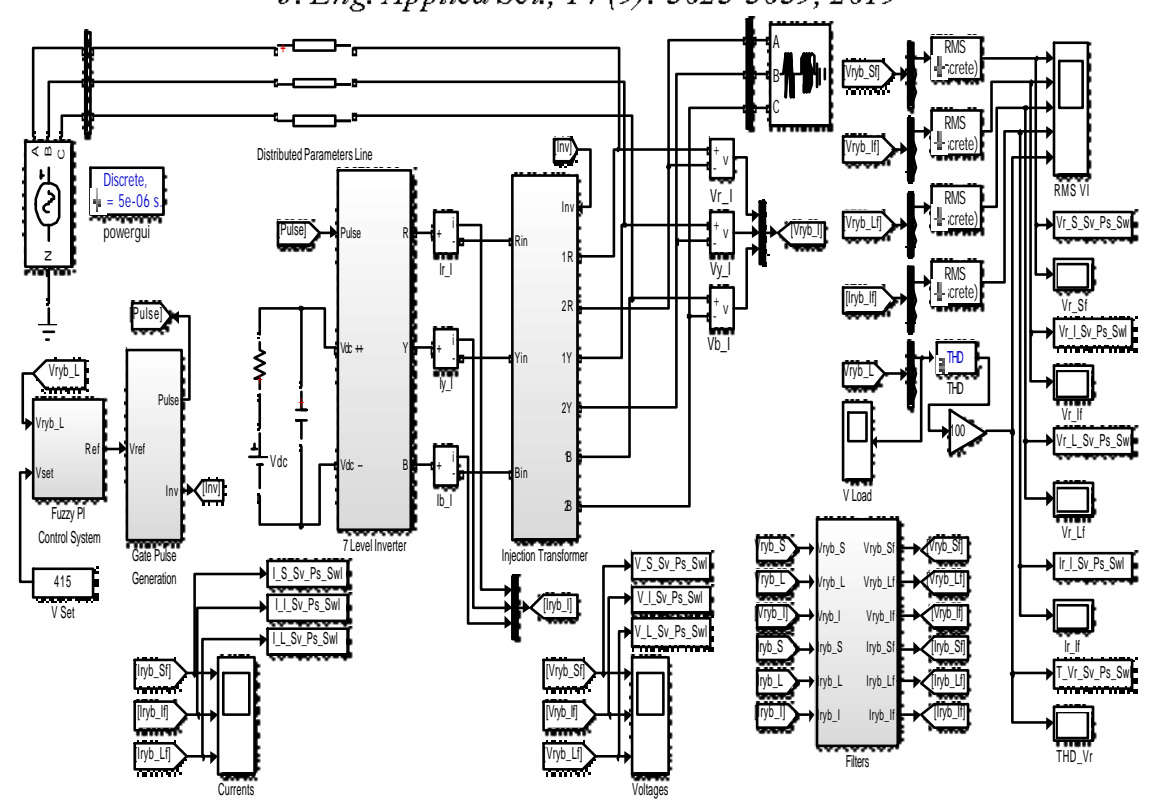

Fig. 4: Simulation diagram-dynamic voltage restorer

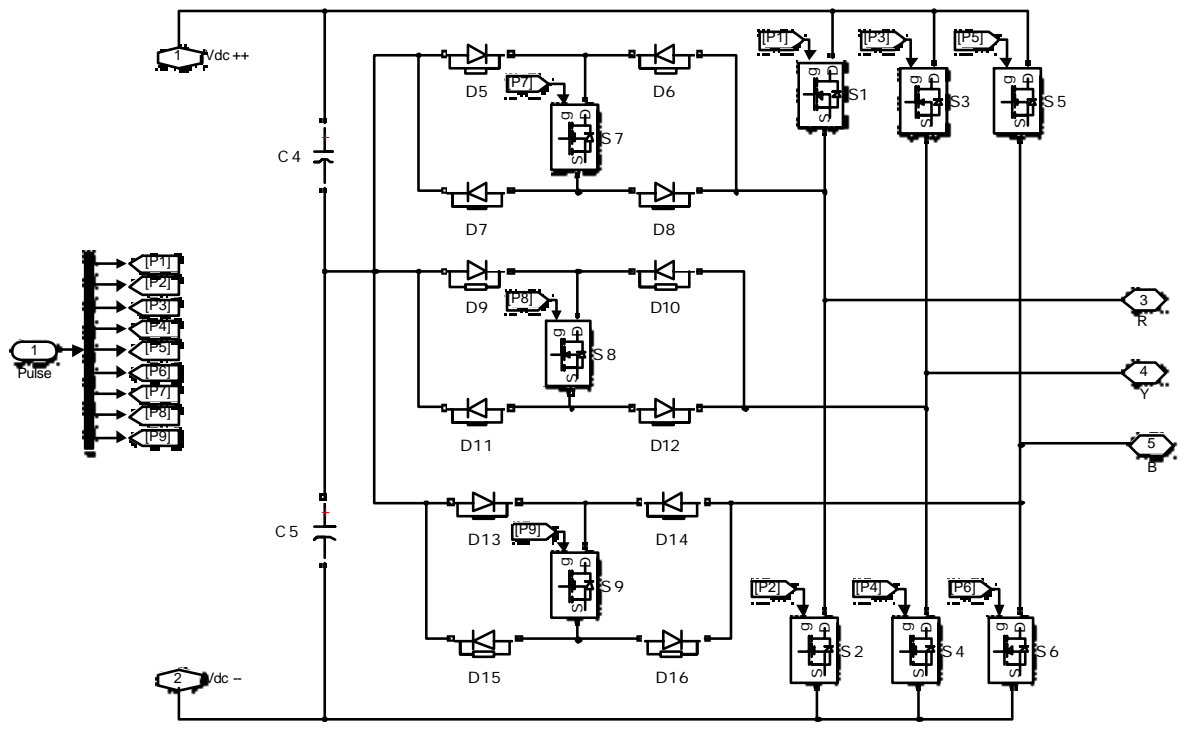

Fig. 5: Seven-level converter based DVR system

be used. Normally, once sag is detected, the target phase of the voltage reference is fixed to the pre-sag phase to ensure that if the reference is tracked correctly then the load voltage phase will remain unaltered. In this study, the control strategy applies the pre-sag compensation to maintain the pre fault value. The simulation diagrams of voltage sag and swell in closed loop system is as shown Fig. 4.

Dynamic Voltage Restorer (DVR): Is one of the most efficient and effective contemporary custom power devices used in power distribution networks. This study mainly discusses about the Power Quality (PQ) problems mitigation algorithm (Fig. 5 and Table 3 ).
Table 3: Switching states for seven level inverter Switches

\begin{tabular}{lccccccccc} 
Time slot & S1 & S2 & S3 & S4 & S5 & S6 & S7 & S8 & S9 \\
\hline T1 & 1 & 0 & 0 & 1 & 1 & 0 & 1 & 1 & 0 \\
T2 & 1 & 0 & 0 & 1 & 1 & 0 & 0 & 1 & 1 \\
T3 & 1 & 0 & 0 & 1 & 0 & 1 & 1 & 0 & 1 \\
T4 & 1 & 0 & 0 & 1 & 0 & 1 & 1 & 1 & 0 \\
T5 & 1 & 0 & 1 & 0 & 0 & 1 & 0 & 1 & 1 \\
T6 & 1 & 0 & 1 & 0 & 0 & 1 & 1 & 0 & 1 \\
T7 & 0 & 1 & 1 & 0 & 0 & 1 & 1 & 1 & 0 \\
T8 & 0 & 1 & 1 & 0 & 0 & 1 & 0 & 1 & 1 \\
T9 & 0 & 1 & 1 & 0 & 1 & 0 & 1 & 0 & 1 \\
T10 & 0 & 1 & 1 & 0 & 1 & 0 & 1 & 1 & 0 \\
T11 & 0 & 1 & 0 & 1 & 1 & 0 & 0 & 1 & 1 \\
T12 & 0 & 1 & 0 & 1 & 1 & 0 & 1 & 0 & 1 \\
\hline
\end{tabular}


Source side power quality problems can be regulated when these voltages are injected in series with a distribution feeder by a Voltage Source Inverter (VSI) with SPWM, control, third order injected SPWM and third order injected phase shift SPWM and there by regulating the voltage at the load terminals. This technique analyse the power circuit, possible control limitations and control targets before providing the compensating control through DVR. The multilevel inverter is chosen for their following merits like less distorted output, low $\mathrm{dv} / \mathrm{dt}$, low distorted input current and smaller common mode voltage.

\section{RESULTS AND DISCUSSION}

The control scheme of the DVR is implemented through derived reference load terminal voltages. The multi-level scheme is a trouble-free design. Simulation results carried out by MATLAB with its Simulink and Sim Power System (SPS) tool boxes to verify the performance of the multi-level method.

Case 1: Mitigation of power quality problems by DVR with SPWM.

Case 2: Mitigation of power quality problems by DVR with third order injected SPWM.

Case 3: Mitigation of power quality problems by DVR with third order injected phase shift SPWM. From the above figures i.e., Fig 6-29 it is observed that, first, waveform is the voltage sag/swell is introduced at $0.1 \mathrm{sec}$ and continued up to $0.4 \mathrm{sec}$ for the time period of $0.3 \mathrm{sec}$. Second, waveform is the voltage induced is produced at $0.1 \mathrm{sec}$ and continued up to $0.4 \mathrm{sec}$ for the time period of $0.3 \mathrm{sec}$, third, wave form is the voltage level of load voltage from the time period $0.025-0.5 \mathrm{sec}$ is maintained required level.
Experimental power circuit 3 phase DVR: The following are the main components used the experimental power circuit 3 phase DVR:

- Signal conditioning circuit

- Source transformers

- ARM micro controller

- DC link

- Series inverter

- Injection transformers

- Source transformers

- Pulse driver

- Line feeders

- Resistive load

As shown in Fig. 30, the hardware block diagram mainly consists of LPC2148-ARM (Advanced RISC machine) controller as CPU (Central Processing Unit) equipped with 2-line and LCD control keys. Potential transformers are used to apprehend the source and load voltages. They are further given to internal analog to digital converter of ARM controller and after signal conditioning. To apprehend the zero crossing of $\mathrm{AC}$ voltage and also to progress an interrupt signal to ARM controller a zero crossing detector is used. The main objective of ZCD is to adjust the generated wave of inverter for every start of each source cycle. By acquiring the signal of interrupt the output of the inverter will be adjusted with positive source cycle for sag condition and negative source cycle for swell condition. Zero crossing detectors are provided at each single phase. To choose the required or necessary sag and swell mode of operation various control keys are used. Apart from selection they are also used set the required voltage in the system. LCD displays the ideal and practical voltages and the required message during operation. For practical analysis, a 3-phase star connected source of rating $230 \mathrm{~V} / 48 \mathrm{~V}, 3 \mathrm{~A}$ per phase and 1 oad as 3-phase star connected resistive with rating $48 \Omega, 48 \mathrm{~W}$ per phase is selected as AC source

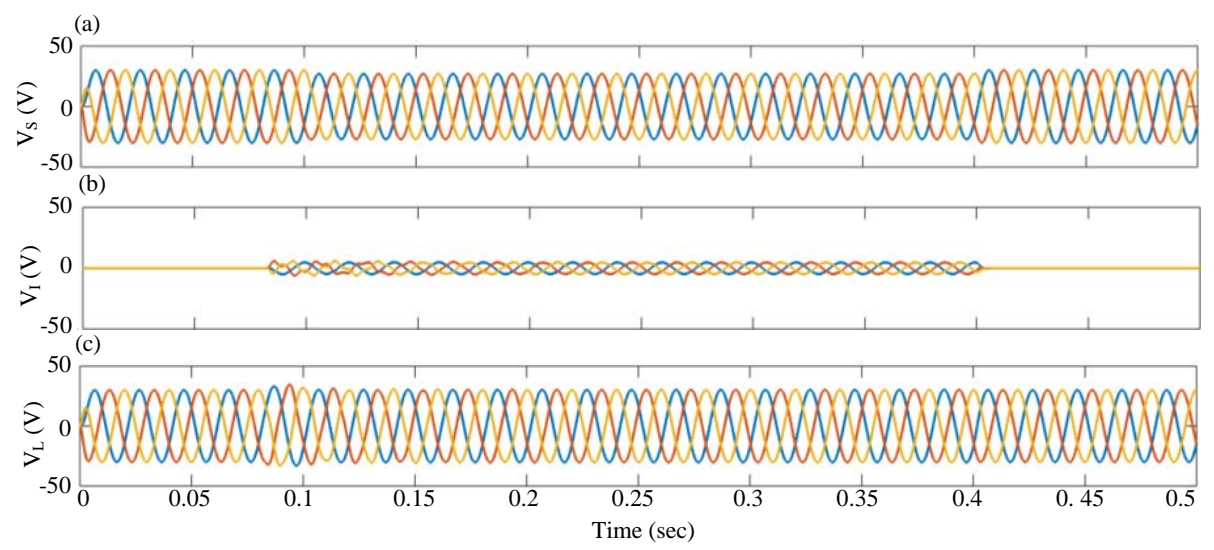

Fig. 6: a-c) Imulation results-DVR with SPWM for sag (10\%) voltage 


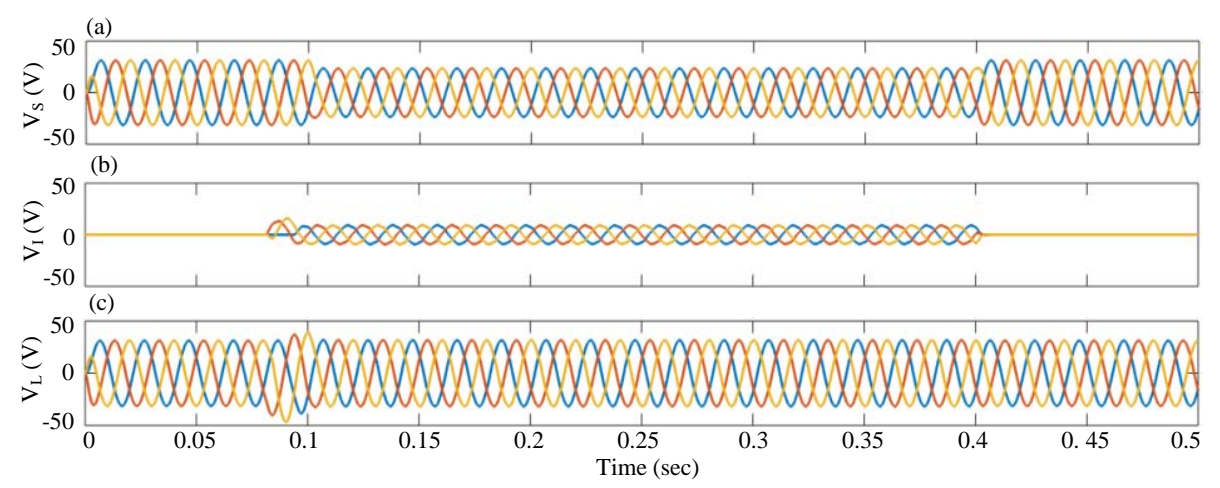

Fig. 7: a-c) Simulation results-DVR with SPWM for sag (25\%) voltage

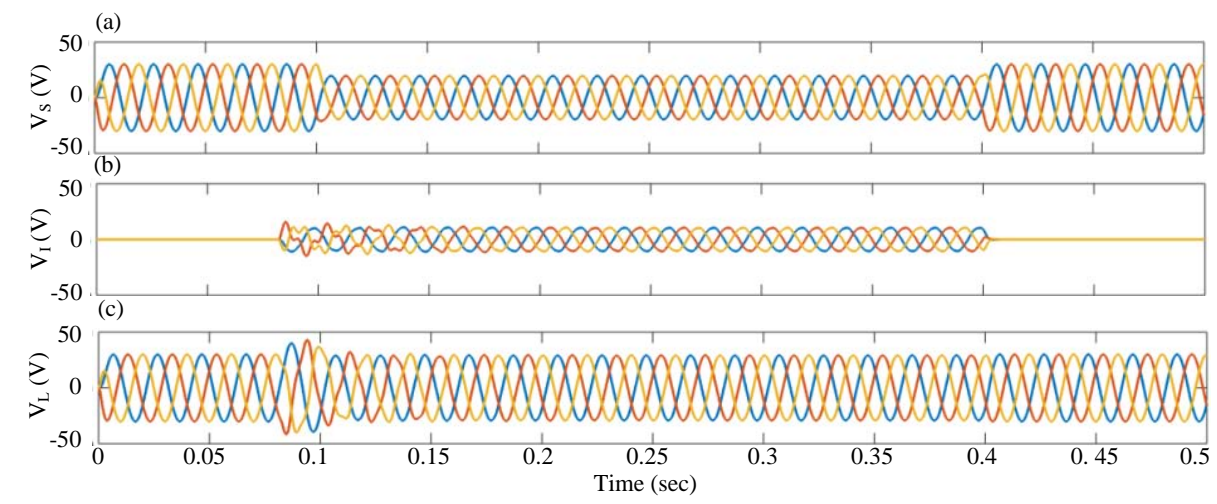

Fig. 8: a-c) Simulation results-DVR with SPWM for sag (35\%) voltage

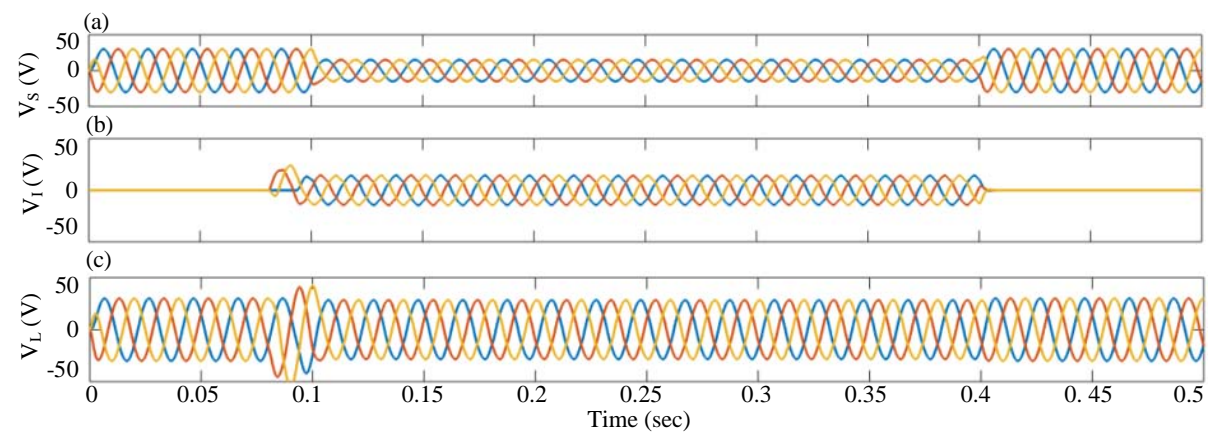

Fig. 9: a-c) Simulation results-DVR with SPWM for sag (50\%) voltage

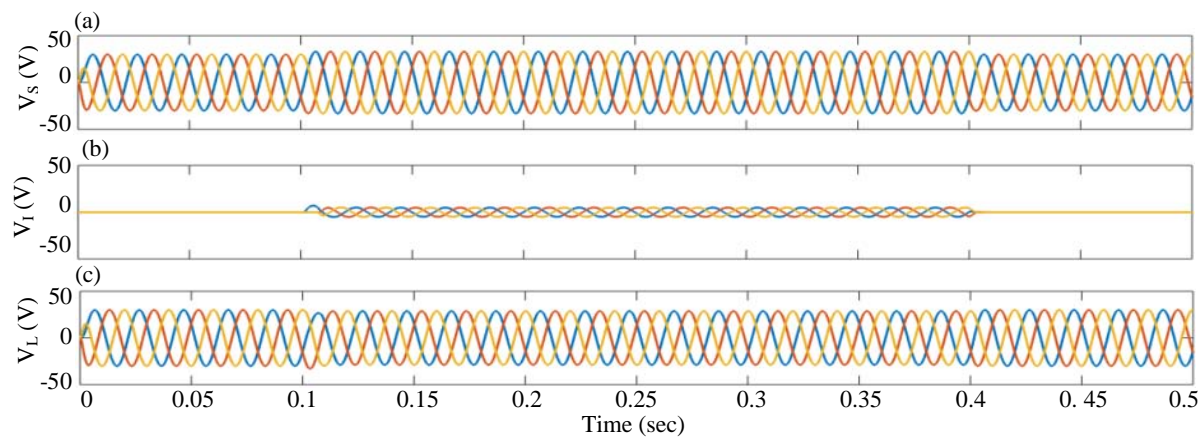

Fig. 10: a-c) Simulation results-DVR with SPWM for swell (10\%) voltage 


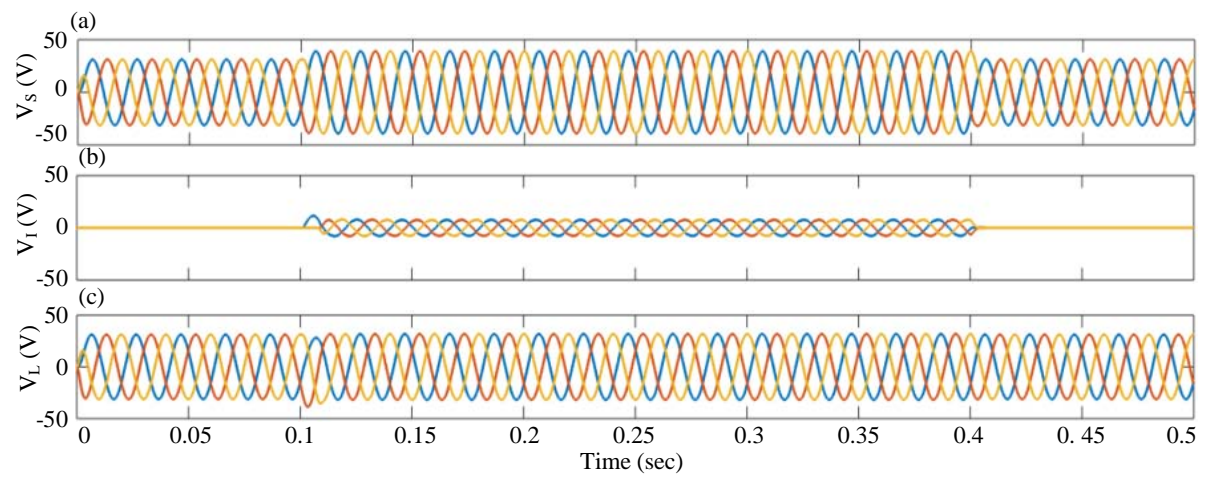

Fig. 11: a-c) Simulation results-DVR with SPWM for swell (25\%) voltage

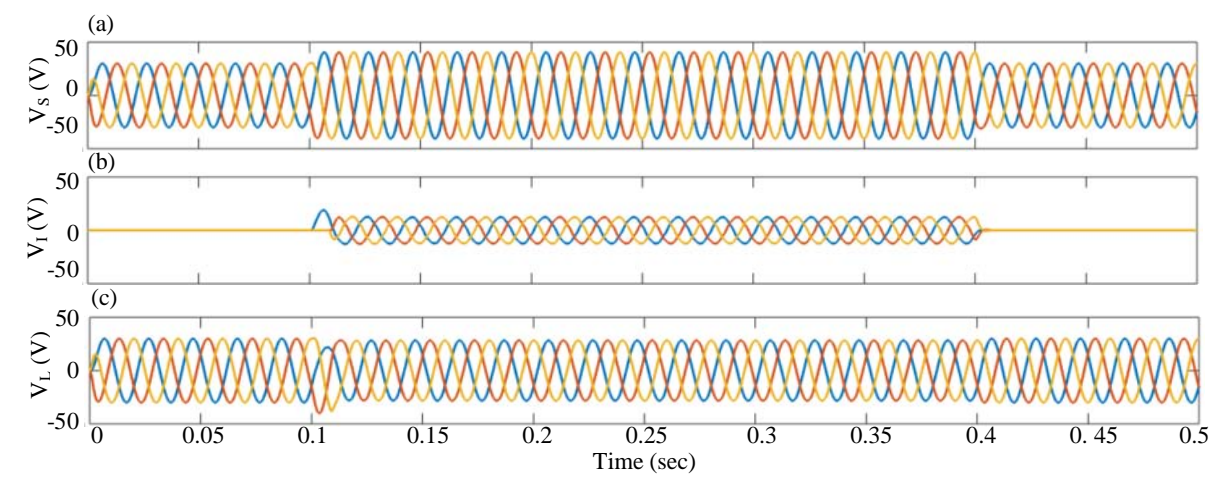

Fig. 12: a-c) Simulation results-DVR with SPWM for swell (35\%) voltage
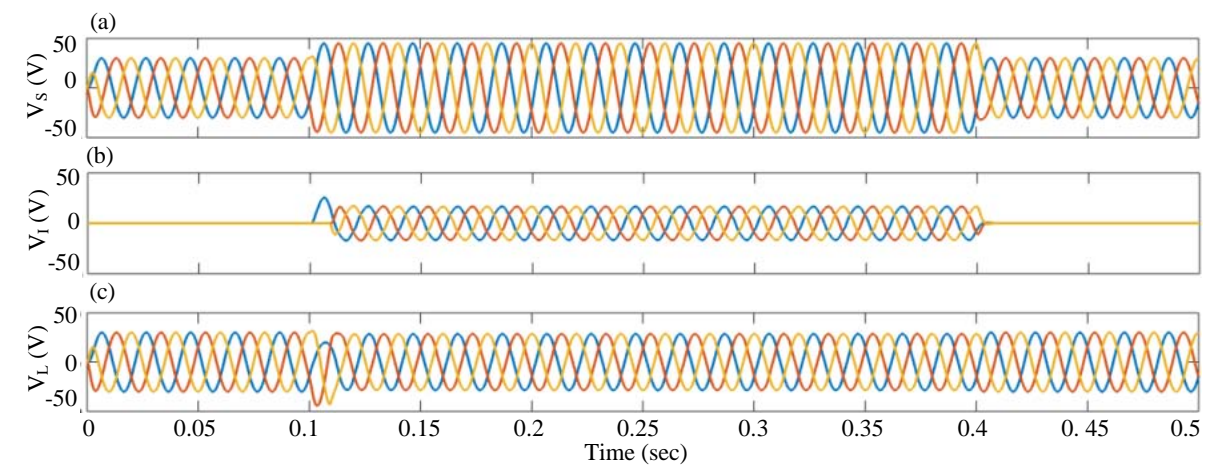

Fig. 13: a-c) Simulation results-DVR with SPWM for swell (50\%) voltage

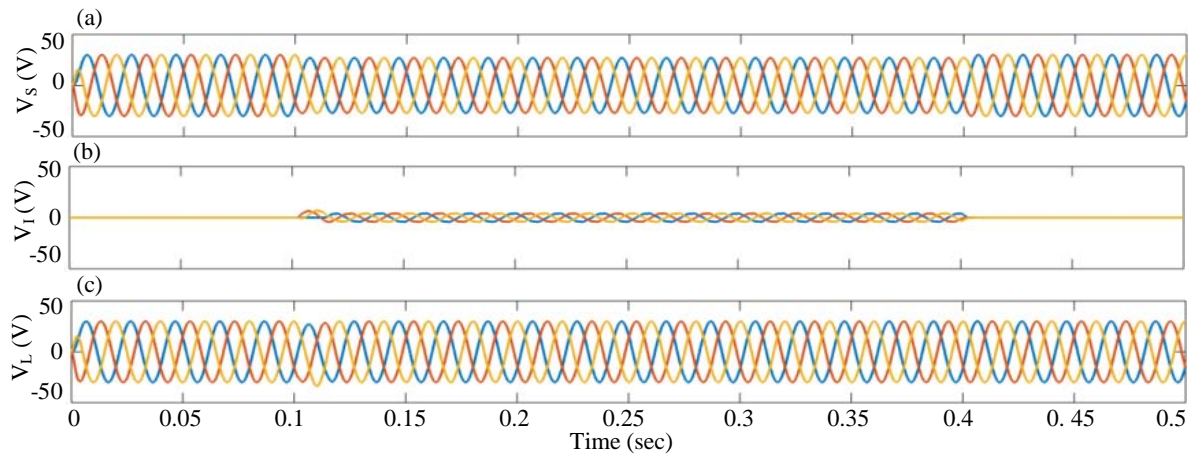

Fig. 14: a-c) Simulation results-DVR with third order harmonics injected SPWM for sag (10\%) voltage 


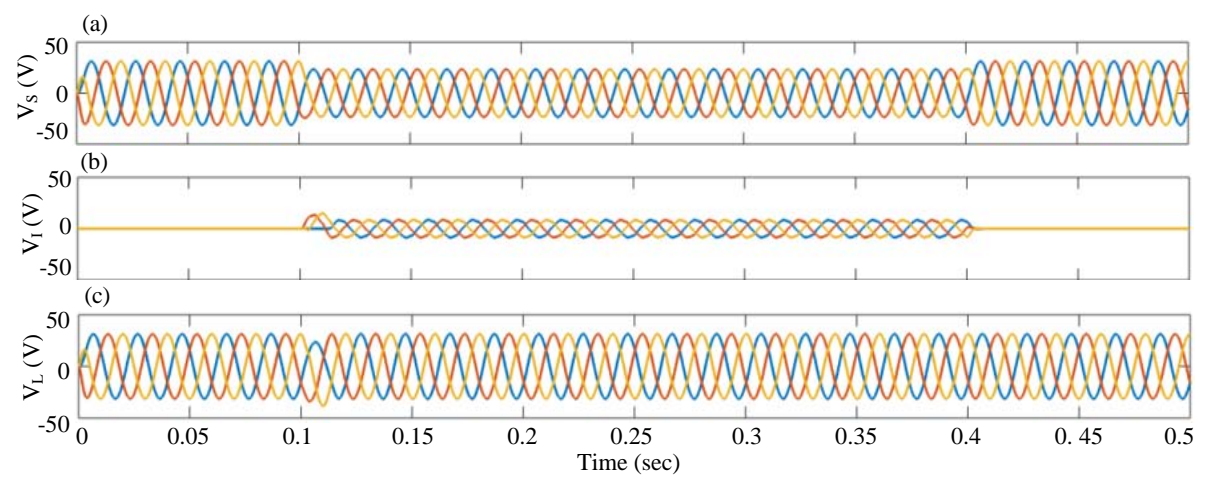

Fig. 15: a-c) Simulation results-DVR with third order harmonics injected SPWM for sag (25\%) voltage

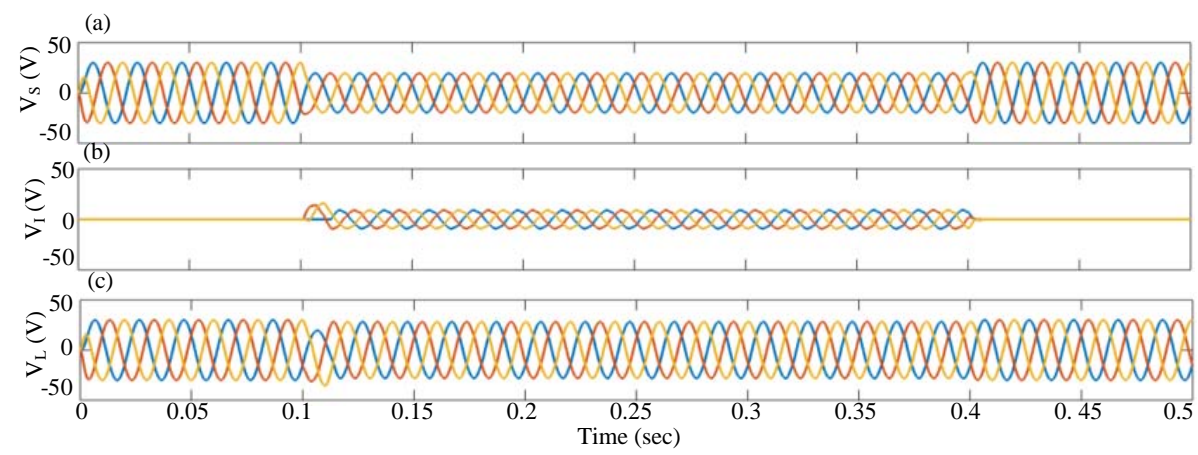

Fig. 16: a-c) Simulation results-DVR with third order harmonics injected SPWM for sag (35\%) voltage

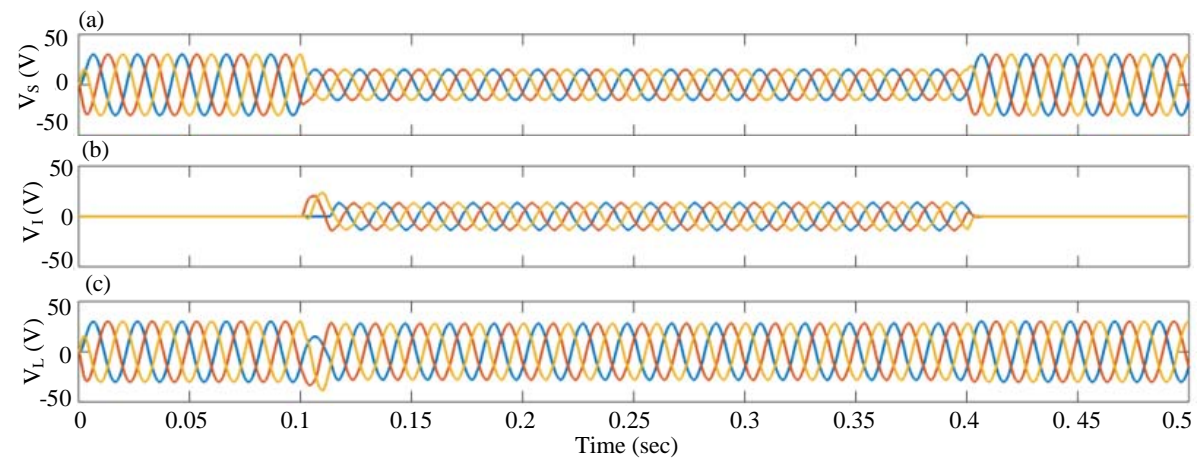

Fig. 17: a-c) Simulation results-DVR with third order harmonics injected SPWM for sag (50\%) voltage

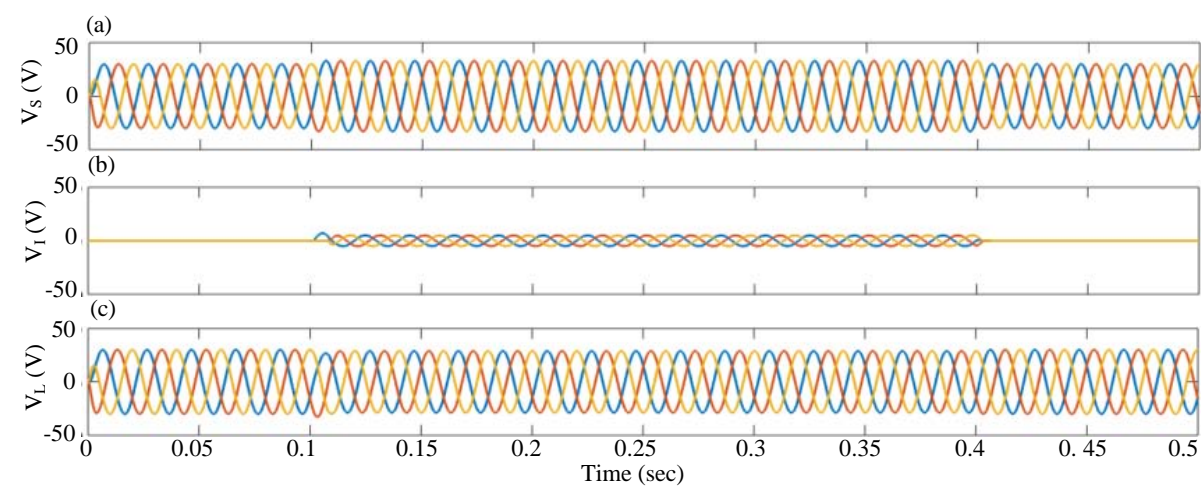

Fig. 18: a-c) Simulation results-DVR with third order harmonics injected SPWM for swell (10\%) voltage 


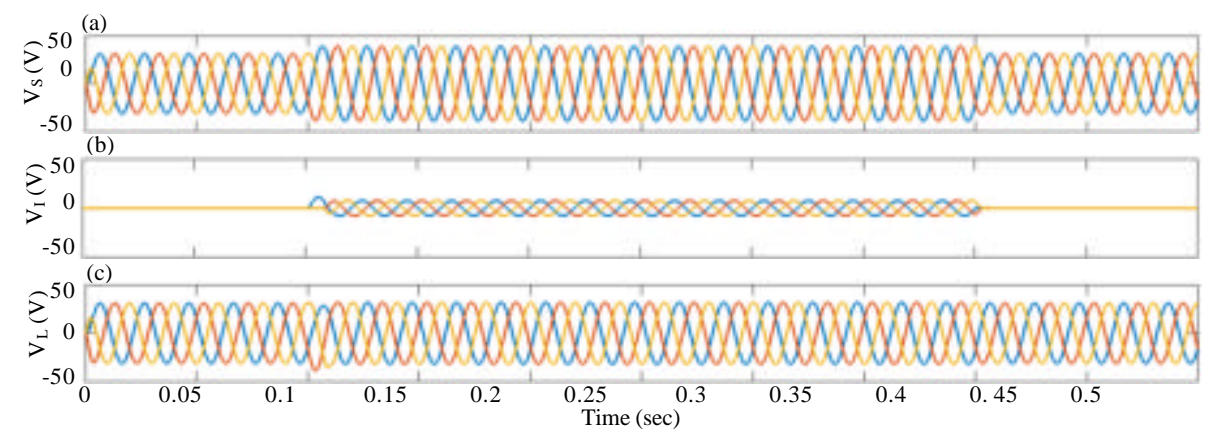

Fig. 19: a-c) Simulation results-DVR with third order harmonics injected SPWM for swell (25\%) voltage

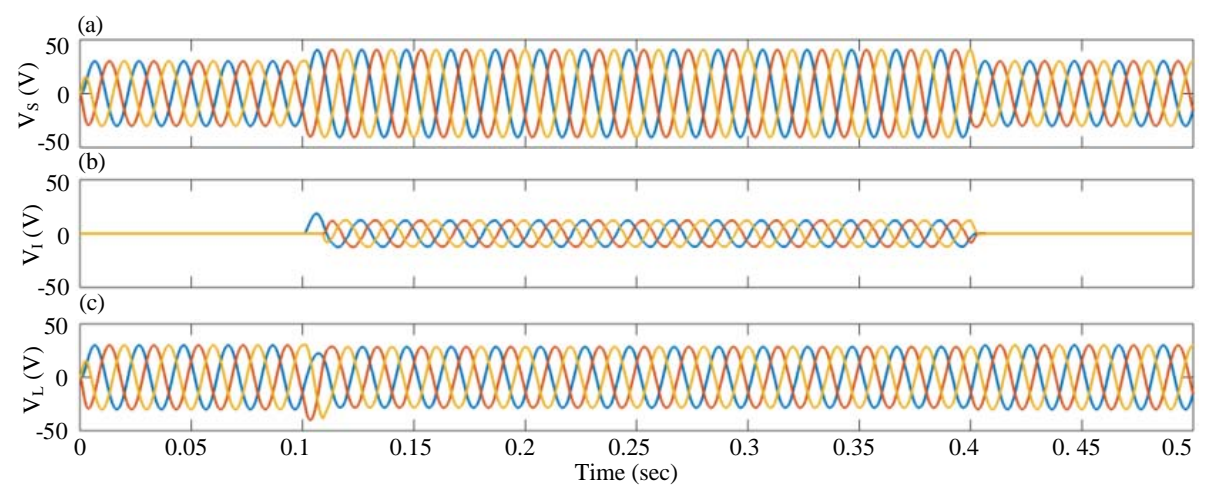

Fig. 20: a-c) Simulation results-DVR with third order harmonics injected SPWM for swell (35\%) voltage

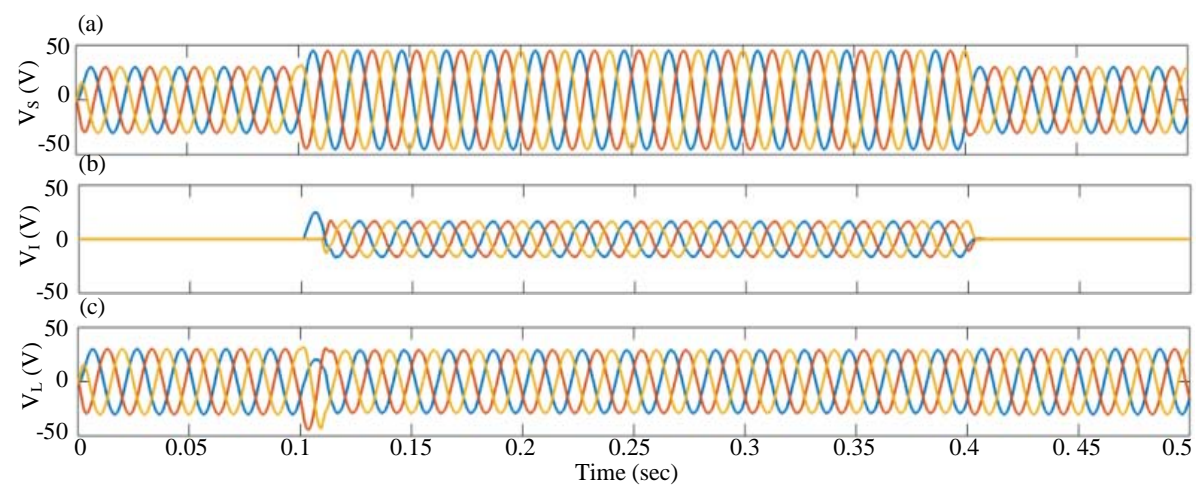

Fig. 21: a-c) Simulation results-DVR with third order harmonics injected SPWM for swell (50\%) voltage

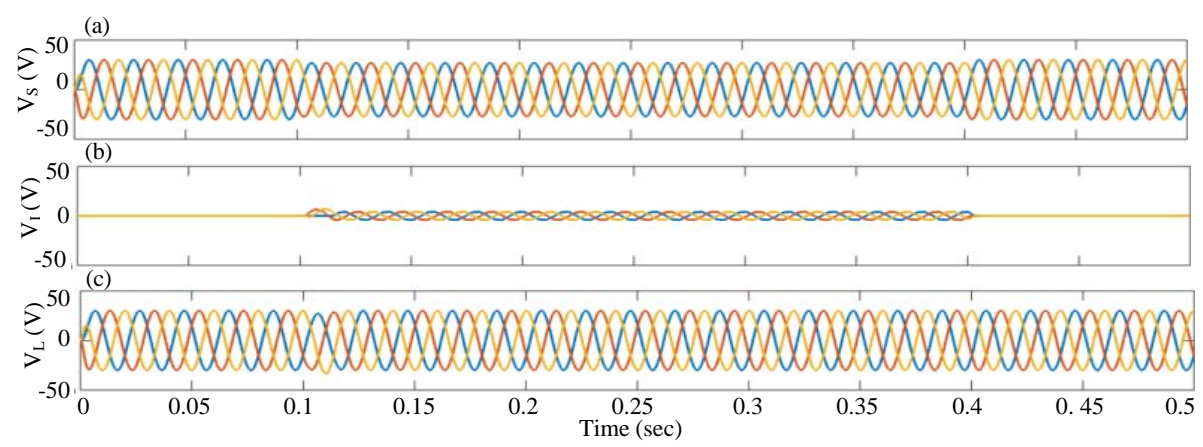

Fig. 22: a-c) Simulation results-DVR with third order harmonics injected phase shift SPWM for sag (10\%) voltage 


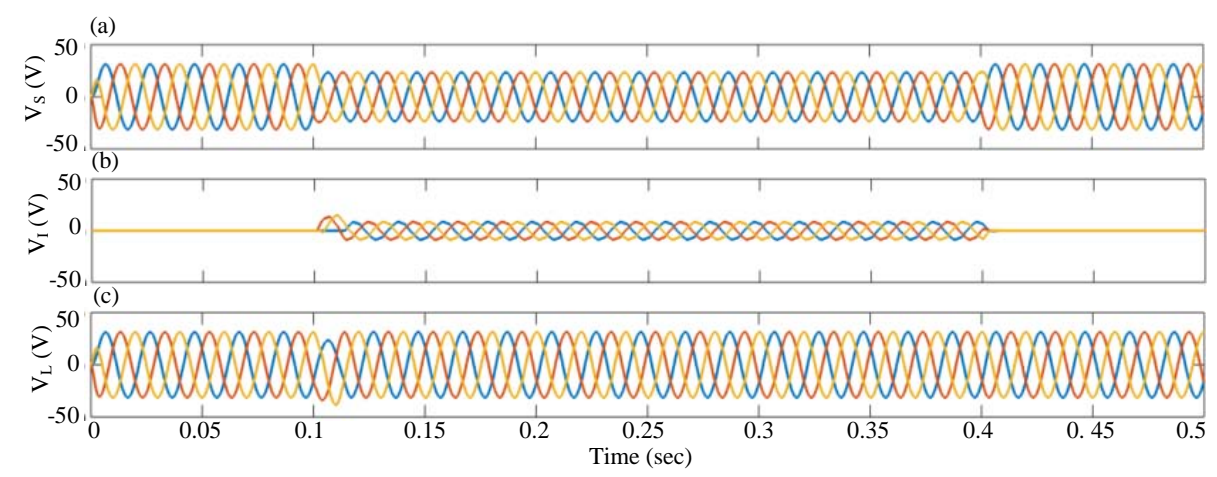

Fig. 23: a-c) Simulation results-DVR with third order harmonics injected phase shift SPWM for sag (25\%) voltage

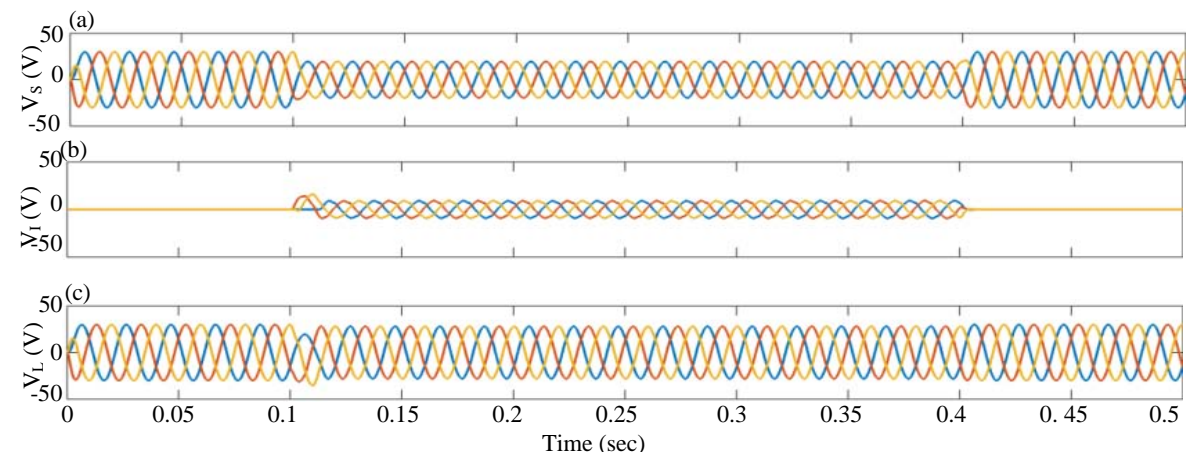

Fig. 24: a-c) Simulation results-DVR with third order harmonics injected phase shift SPWM for sag (35\%) voltage

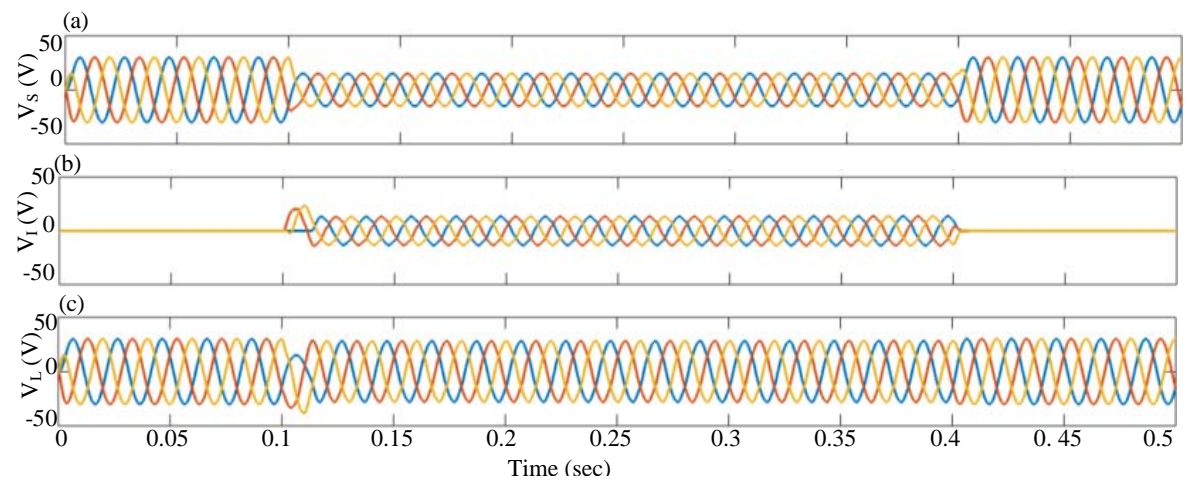

Fig. 25: a-c) Simulation results-DVR with third order harmonics injected phase shift SPWM for sag (50\%) voltage
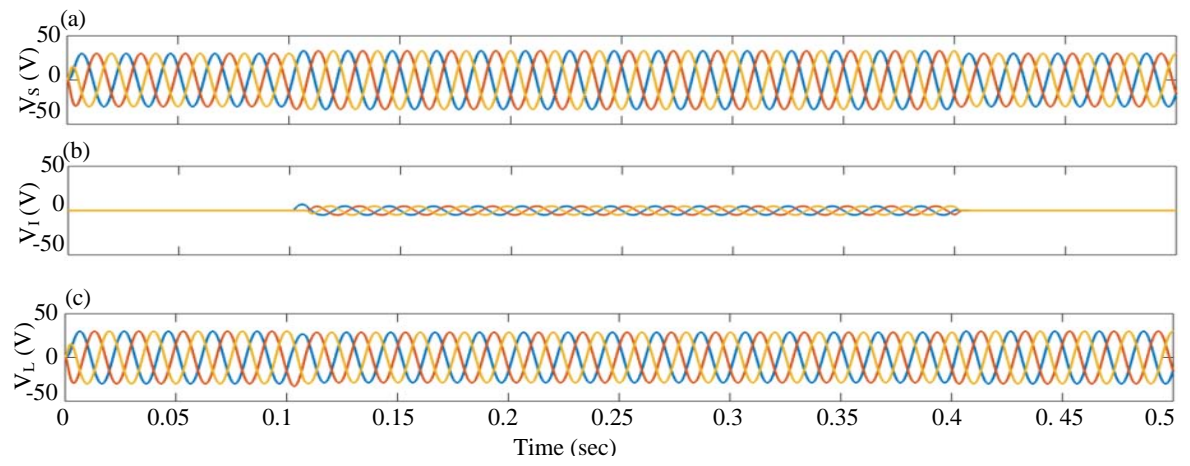

Fig. 26: a-c) Simulation results-DVR with third order harmonics injected phase shift SPWM for swell (10\%) voltage 

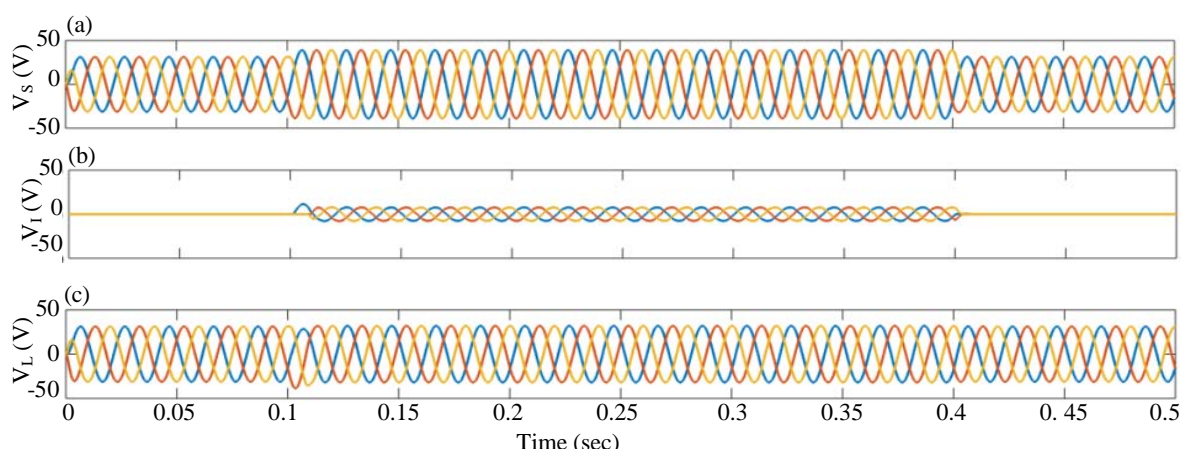

Fig. 27: a-c) Simulation results-DVR with third order harmonics injected phase shift SPWM for swell (25\%) voltage

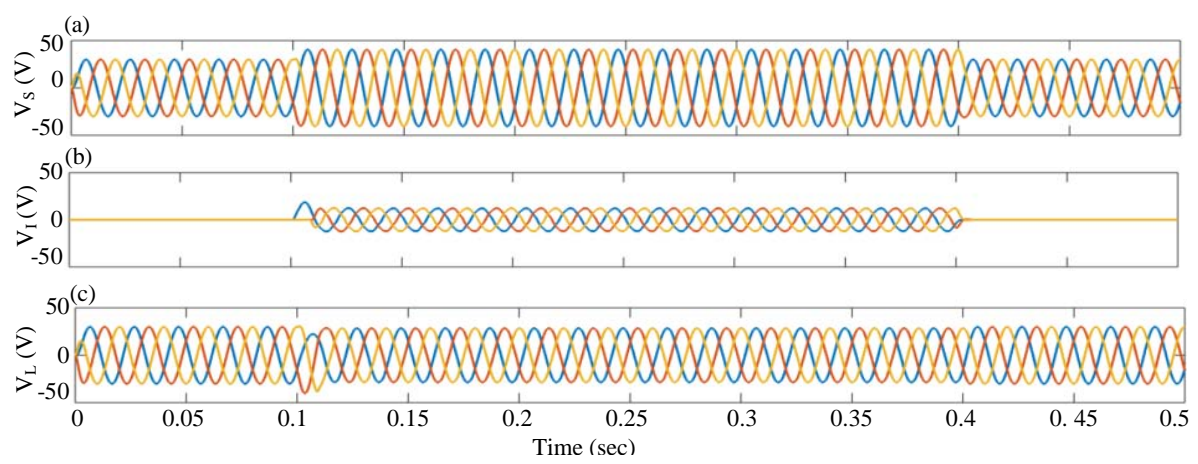

Fig. 28: a-c) Simulation results-DVR with third order harmonics injected phase shift SPWM for swell (35\%) voltage
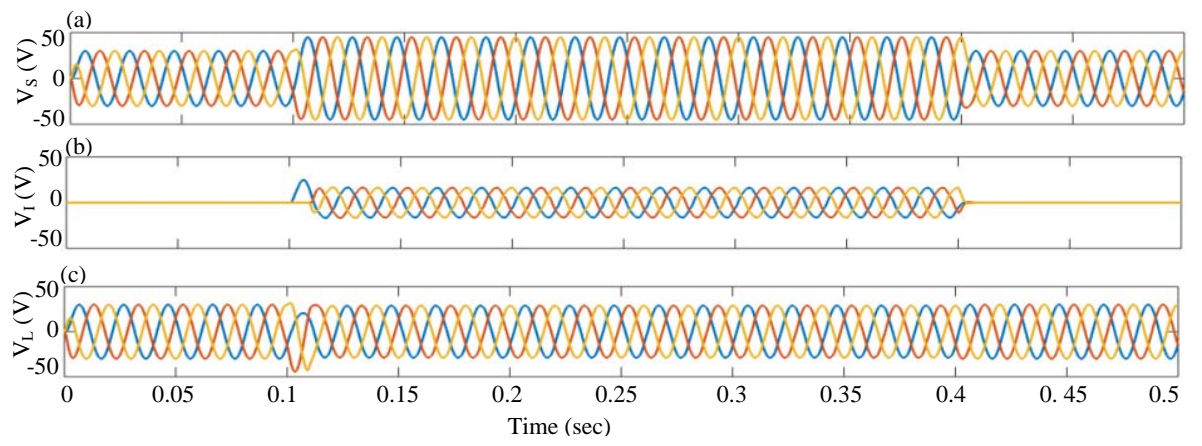

Fig. 29: a-c) Simulation results-DVR with third order harmonics injected phase shift SPWM for swell (50\%) voltage

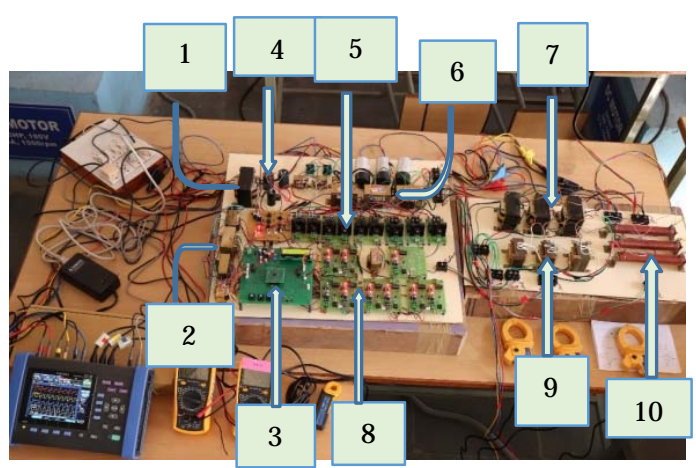

Fig. 30: Experimental 3 phase power circuit DVR load. Injection transformer of rating $48 \mathrm{~V} / 48 \mathrm{~V}, 3 \mathrm{~A}$ per phase is selected. In this experimental analysis a 7-level inverter is designed by coupling the three bidirectional switches to traditional 6-pulse 3-phase bridge inverter with 6-unidirectional switches. The topography of the designed inverter is shown in Table 4. In the designed inverter, the switches S1-6 are the MOSFET IRF460P unidirectional switches with suitable snubber circuit.

Whereas the switches S7-9 are bidirectional switches in which one MOSFET IRF460P power switch and four high frequency switching power diodes UF5408 are used. The traditional 6-pulse inverter produces 5-level phase voltage and the arrangement of bidirectional switch to each phase produces an extra level in positive and 
negative cycle. Hence, it results in increase in number of voltage levels in phase voltage to seven and therefore, minimizes the content of harmonics. Two series Capacitors $\mathrm{Cl}$ and $\mathrm{C} 2$ with identical rating are connected across the inverter DC source to produce the necessary voltages required for bidirectional switches.

ARM controller produces gate pulses of a voltage level $3.3 \mathrm{~V}$. But the MOSFETs desires a gate pulse of magnitude $10-20 \mathrm{~V}$. Hence, to overcome this problem, a gate driver circuit with OPTO coupler is designed to increase the level of gate pulse suitable for MOSFETs and

\begin{tabular}{|c|c|c|}
\hline Name of the equipment & Range & Qty \\
\hline Power Transformer (PT) & $230 \mathrm{~V} / 24 \mathrm{~V}-0-24 \mathrm{~V}, 3 \mathrm{~A}$ & 1 \\
\hline Inductance (Line impedance) & $4 \mathrm{mH}$ & 3 \\
\hline Resistive load & $96 \Omega$ & 3 \\
\hline \multicolumn{3}{|l|}{ DC link capacitors } \\
\hline Filter capacitor & $2220 \mu \mathrm{F}, 100 \mathrm{~V}$ & 1 \\
\hline Capacitance & $10000 \mu \mathrm{F}, 50 \mathrm{~V}$ & 2 \\
\hline \multicolumn{3}{|l|}{ Series inverter } \\
\hline Unidirectional MOSFET & IRF $460-460 \mathrm{~V}, \mathrm{DC}, 10 \mathrm{Amps}$ & 6 \\
\hline Bidirectional MOSFET & IRF $460-460 \mathrm{~V}, \mathrm{DC}, 10 \mathrm{Amps}$ & 3 \\
\hline \multicolumn{3}{|l|}{ Firing circuit } \\
\hline Diode & IN4007 & 9 \\
\hline Capacitor & $470 \mu \mathrm{F}, 25 \mathrm{~V}$ & 9 \\
\hline Regulator & $7805,5 \mathrm{~V}, 500 \mathrm{~mA}$ & 9 \\
\hline Regulator & $7812,12 \mathrm{~V}, 500 \mathrm{~mA}$ & 9 \\
\hline Filter & $100 \mu \mathrm{F}$ & 9 \\
\hline Opto isolator & N137-8 pin & 9 \\
\hline Transistor & $2 \mathrm{~N} 3904$ & 9 \\
\hline Firing chip component & IC IR2100 & 9 \\
\hline \multicolumn{3}{|l|}{ Signal conditioning circuit } \\
\hline Step down transformer & $230 \mathrm{~V} / 12 \mathrm{~V}, \mathrm{~A}$ & 1 \\
\hline Operational amplifier & LM358 & 1 \\
\hline \multicolumn{3}{|l|}{ Input voltage measurement } \\
\hline Isolation transformer & $9 \mathrm{~V}-0-9 \mathrm{~V} / 9 \mathrm{~V}-0-9 \mathrm{~V}, 500 \mathrm{~mA}$ & 1 \\
\hline $\begin{array}{l}\text { Power supply for } \\
\mu c \text {-Power transformer }\end{array}$ & $230 \mathrm{~V} / 9 \mathrm{~V}, 1 \mathrm{~A}$ & 1 \\
\hline $\begin{array}{l}\text { Power supply for firing } \\
\text { circuit-Step down transformer }\end{array}$ & $230 \mathrm{~V} / 12 \mathrm{~V}, 250 \mathrm{~mA}$ & 2 \\
\hline $\begin{array}{l}\text { Power supply for } \\
\text { signal conditioning circuit }\end{array}$ & $230 \mathrm{~V} / 12 \mathrm{~V}-0-12 \mathrm{~V}, 1 \mathrm{~A}$ & 1 \\
\hline Bridge rectifier & BR1010 & 1 \\
\hline Micro processor & LPC2148-ARM & 1 \\
\hline
\end{tabular}

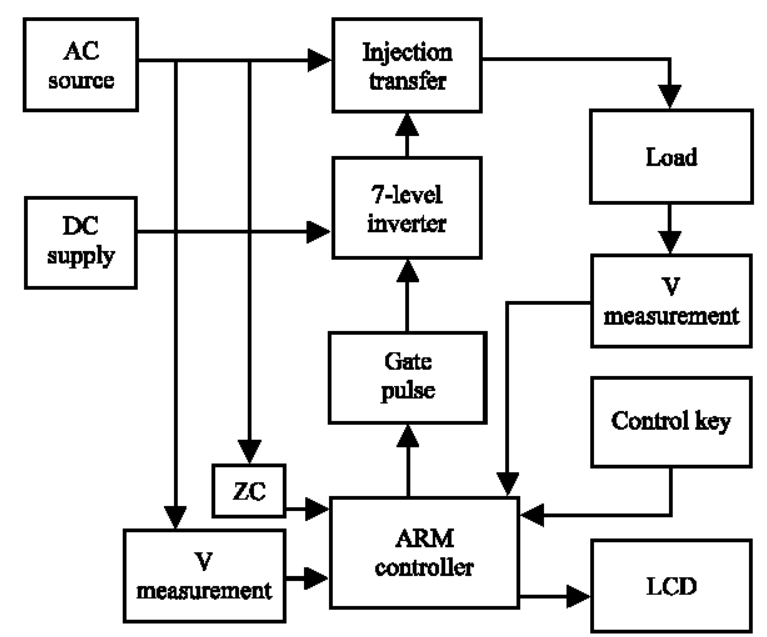

Fig. 31: Hardware block diagram also for isolation of ground. Each and every power switch consists of individual driver circuit with an isolated power supply. Fuzzy-PID controller is used to control the gate switching pulses produced by the ARM controller. In this setup, the timing pulses produced by the internal timer of ARM controller for the time duration of $20 \mathrm{msec}$ $(1 / 50 \mathrm{~Hz}=20 \mathrm{msec})$ is further splitted into 12 time slots ( 6 time slots for positive cycle and 6 for negative cycle). These timing pulses symbolize SVPWM phase angles. By using the PWM unit of ARM controller, $10 \mathrm{kHz}$ modulating triangular pulse width modulation signal is produced. The generated timing pulses can be amplified or modulated externally using OR gates (Fig. 31-49 and Table 5 and 6 ).

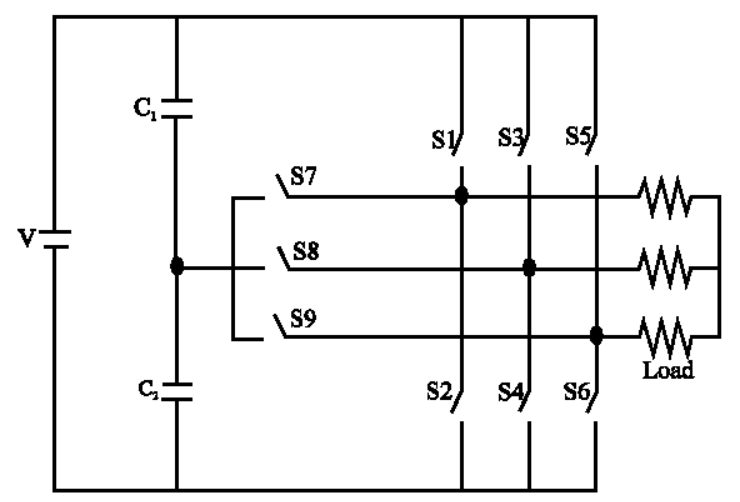

Fig. 32: Topology of 7-level inverter

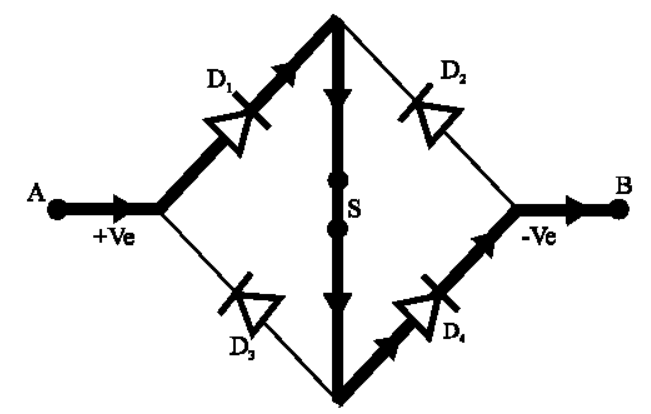

Fig. 33: Conduction a to $b$

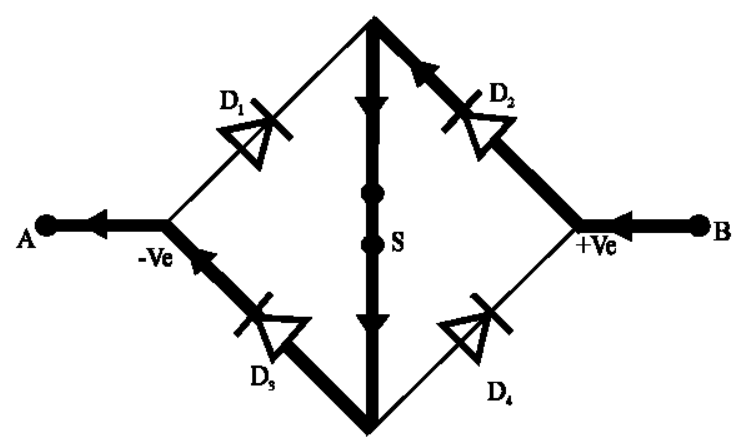

Fig. 34: Conduction $\mathrm{b}$ to $\mathrm{a}$ 


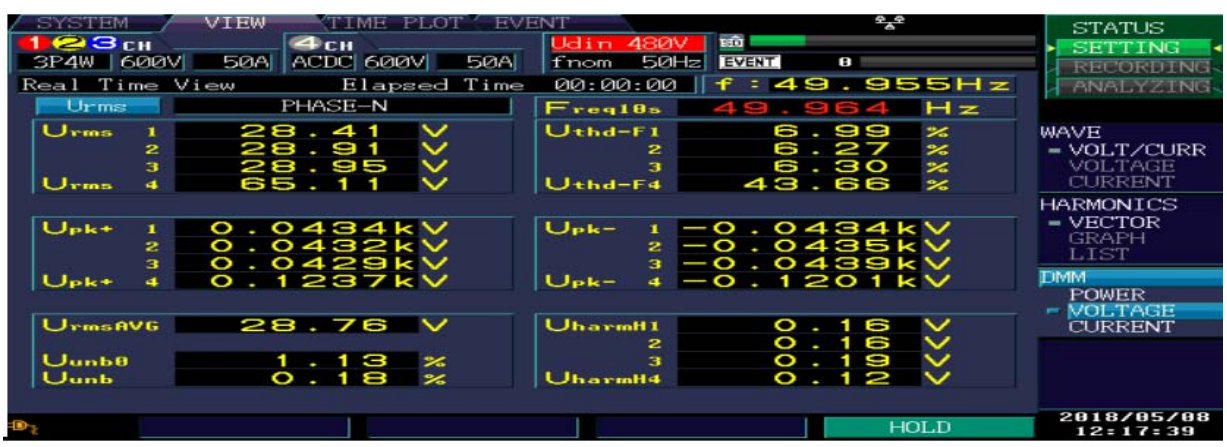

Fig. 35: Experimental results-DVR with SPWM for swell (36\%) Total Harmonic Distortion (THD)

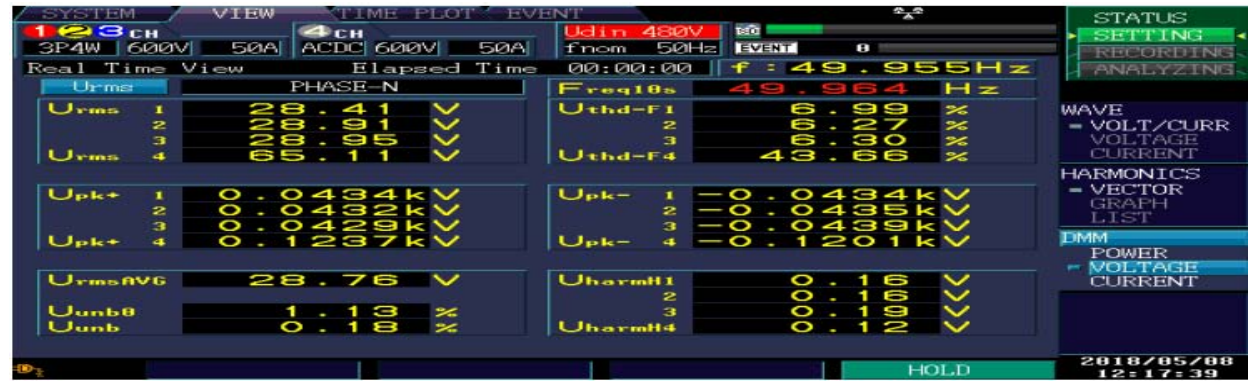

Fig. 36: Experimental results-DVR with SPWM for swell (36\%) voltage without compensation

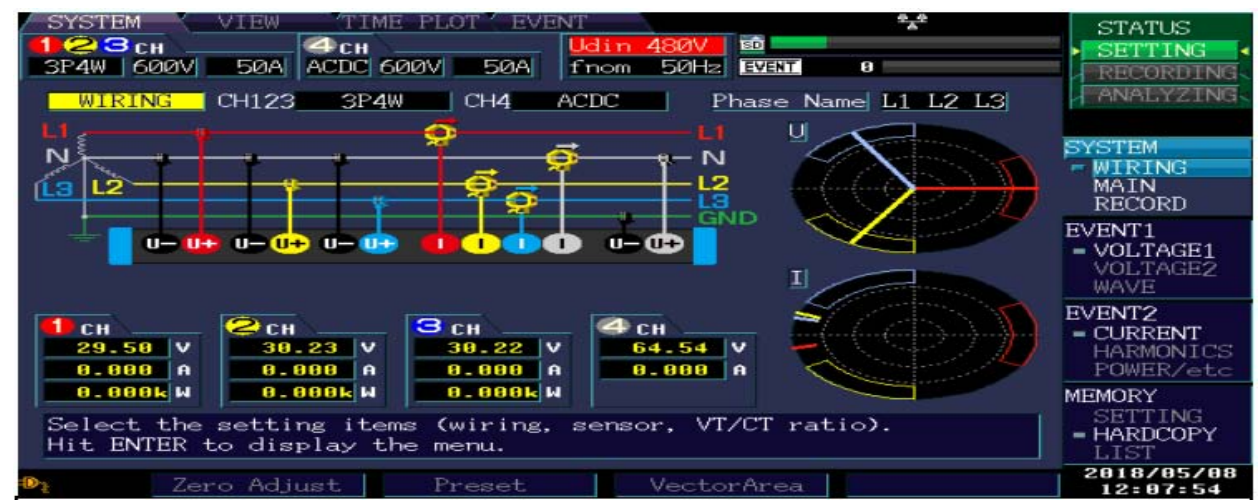

Fig. 37: Experimental results-DVR with SPWM for swell (36\%) voltage with compensation

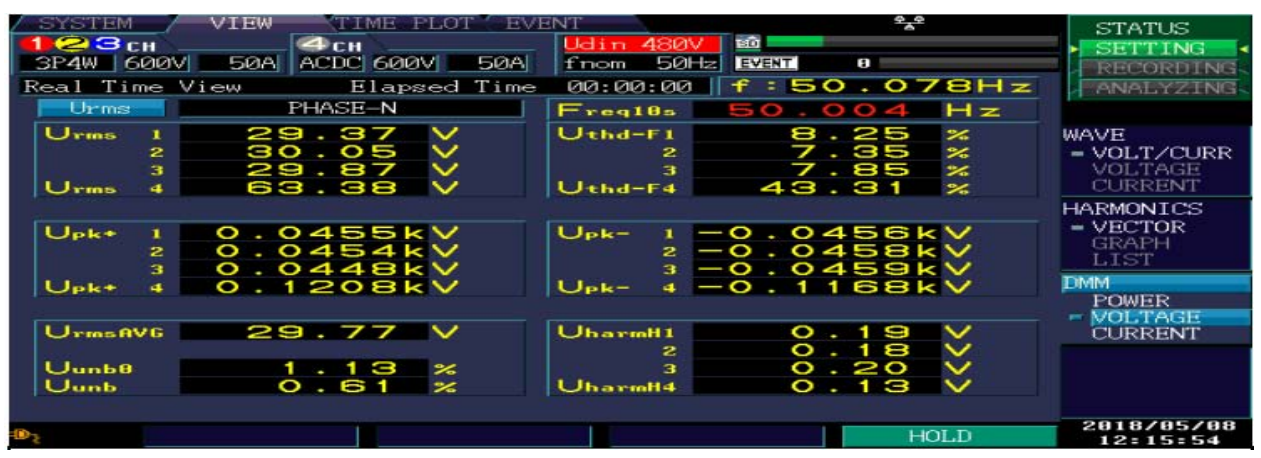

Fig. 38: Experimental results-DVR with SPWM for swell (16\%) Total Harmonic Distortion (THD) 


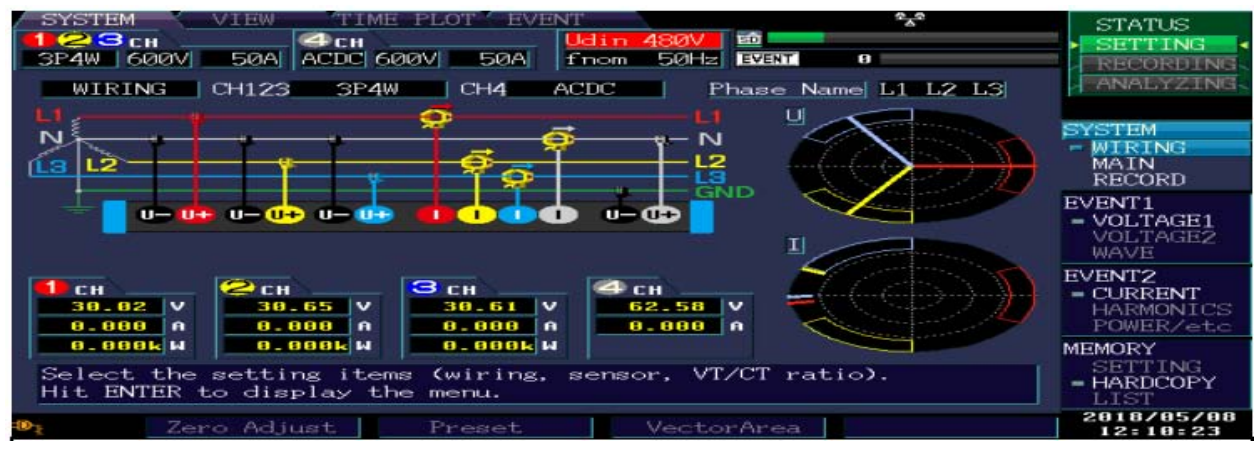

Fig. 39: Experimental results-DVR with SPWM for swell (16\%) voltage without compensation

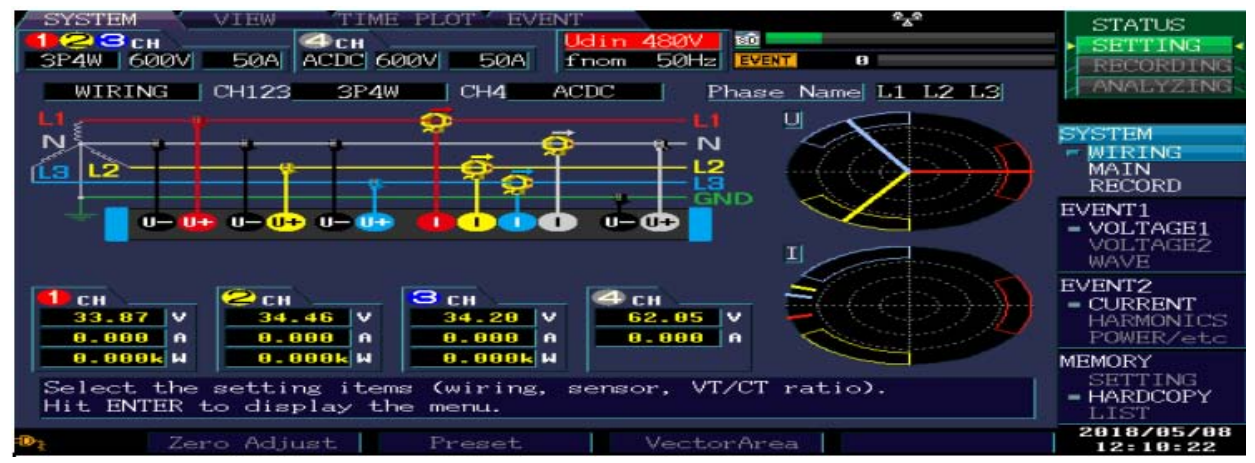

Fig. 40: Experimental results-DVR with SPWM for swell (16\%) voltage with compensation

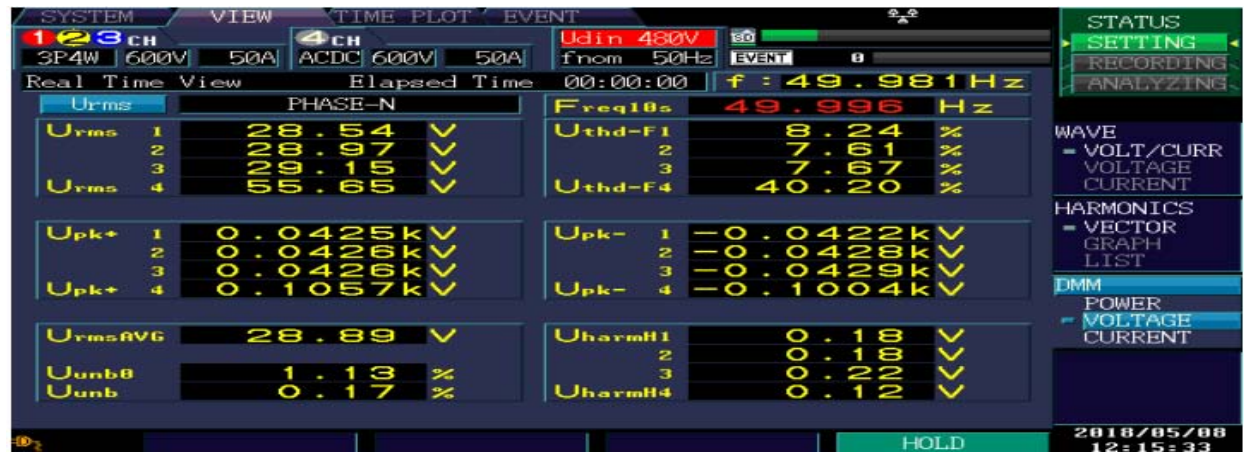

Fig. 41: Experimental results-DVR with SPWM for swell (10\%) Total Harmonic Distortion (THD)

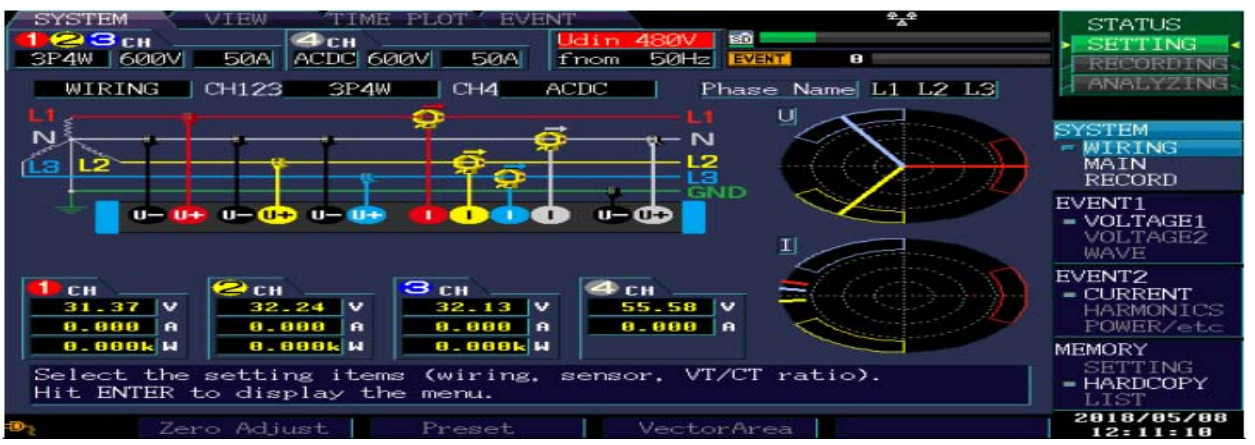

Fig. 42: Experimental results-DVR with SPWM for swell (10\%) voltage without compensation 


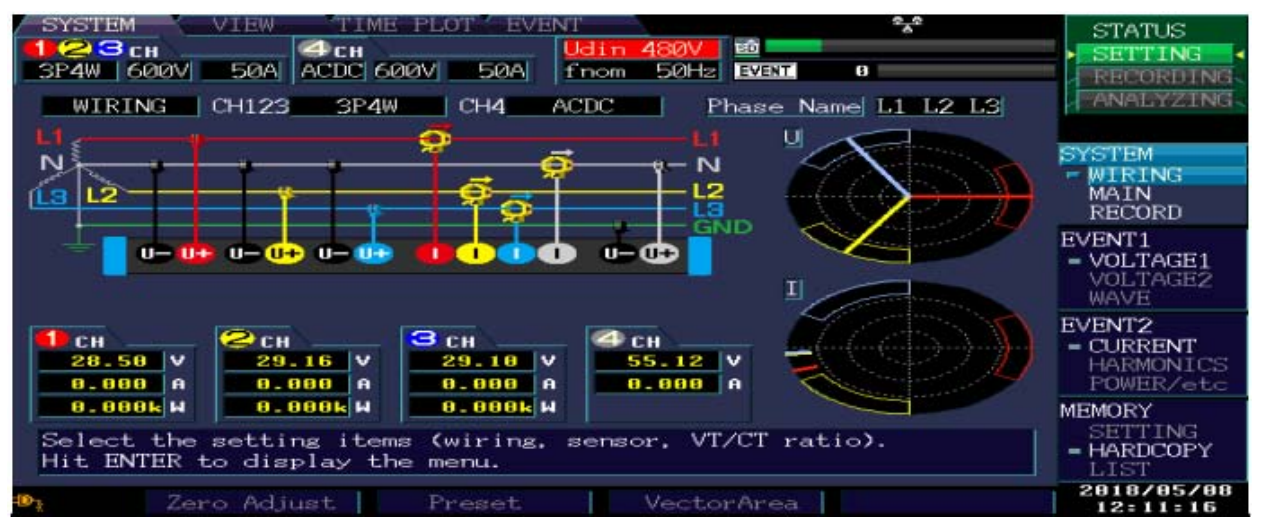

Fig. 43: Experimental results-DVR with SPWM for swell (10\%) voltage with compensation

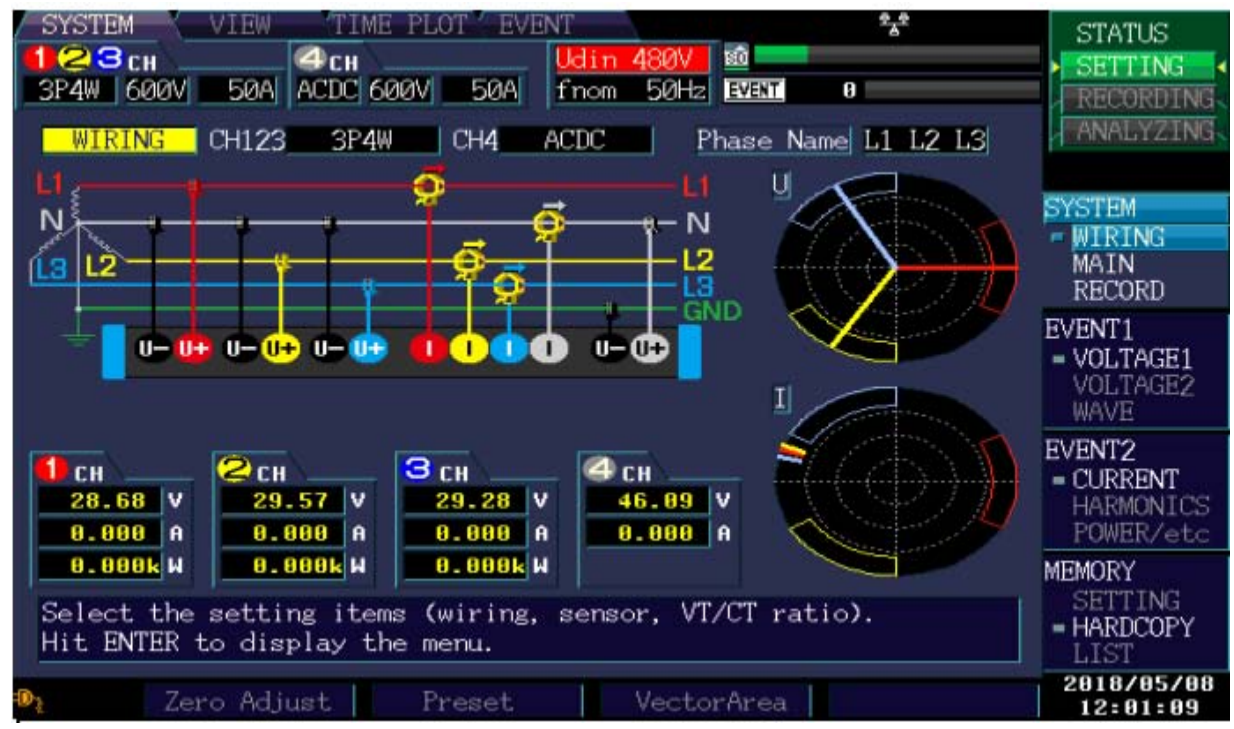

Fig. 44: Experimental results-DVR with SPWM for sag (36\%) voltage without compensation

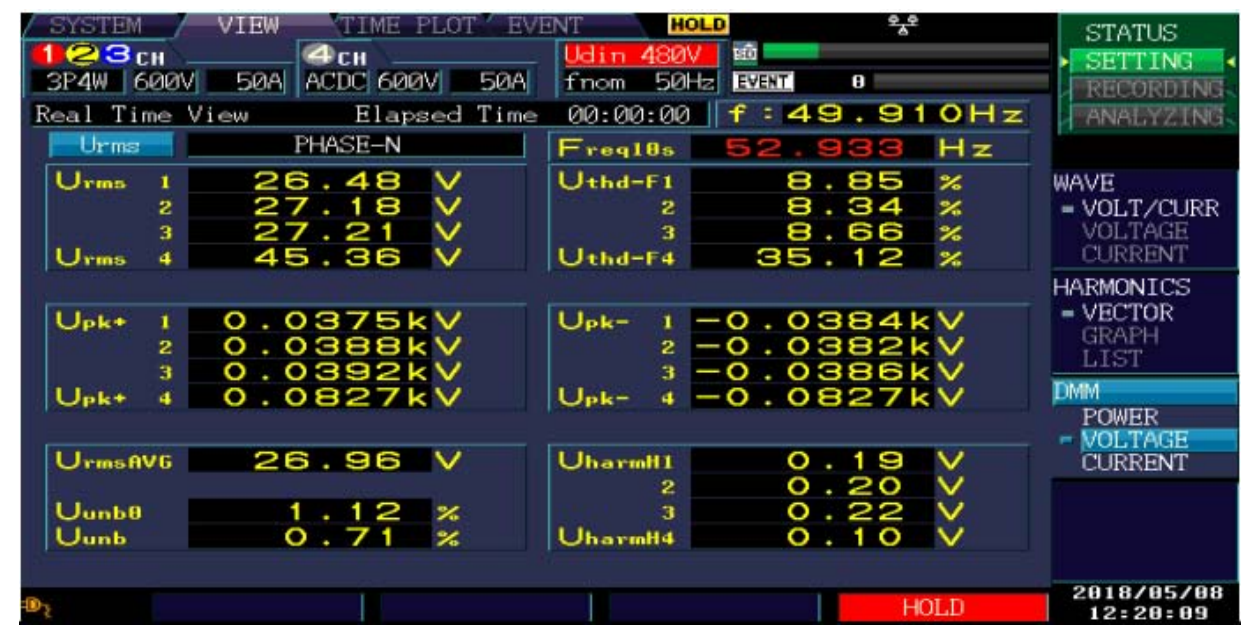

Fig. 45: Experimental results-DVR with SPWM for sag (36\%) Total Harmonic Distortion (THD) 


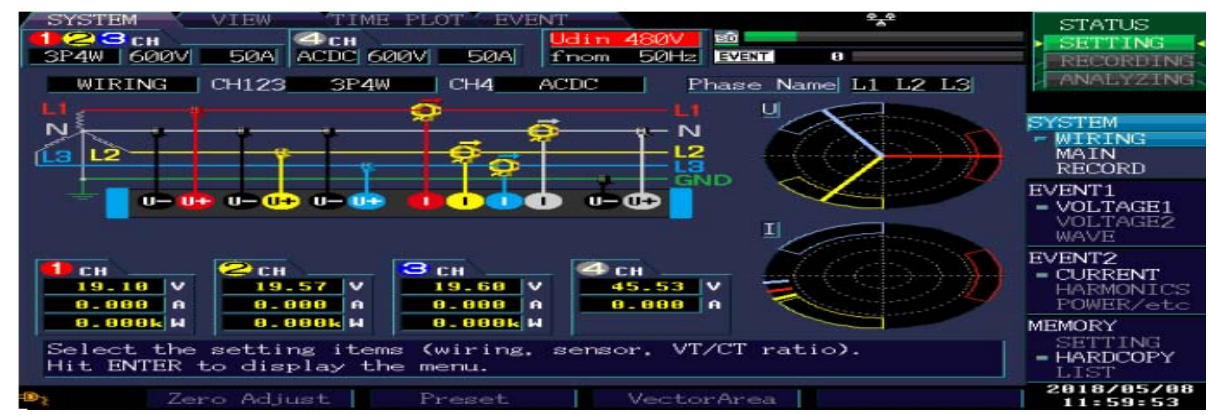

Fig. 46: Experimental results-DVR with SPWM for sag (36\%) voltage with compensation

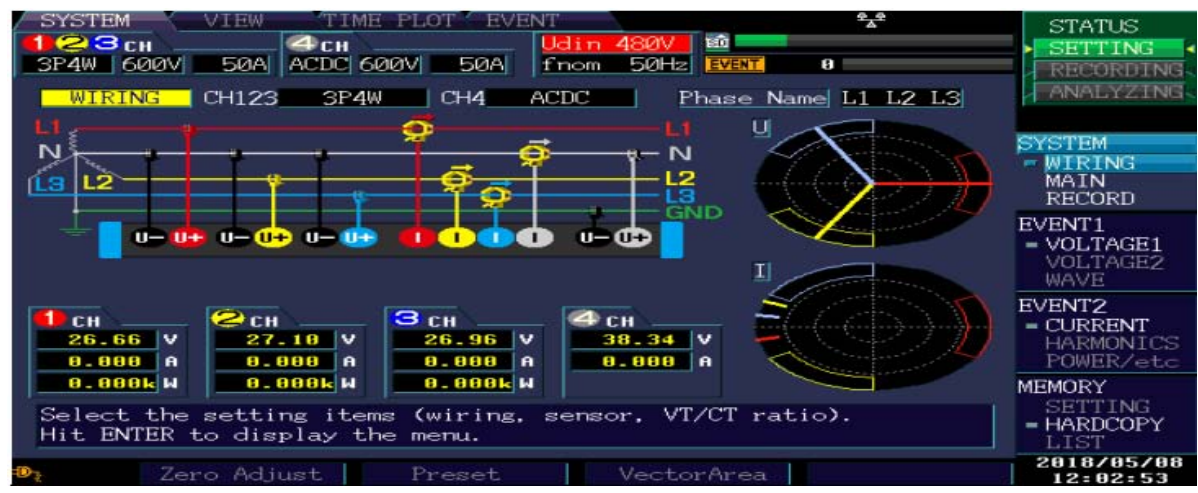

Fig. 47: Experimental results-DVR with SPWM for swell (50\%) voltage without compensation

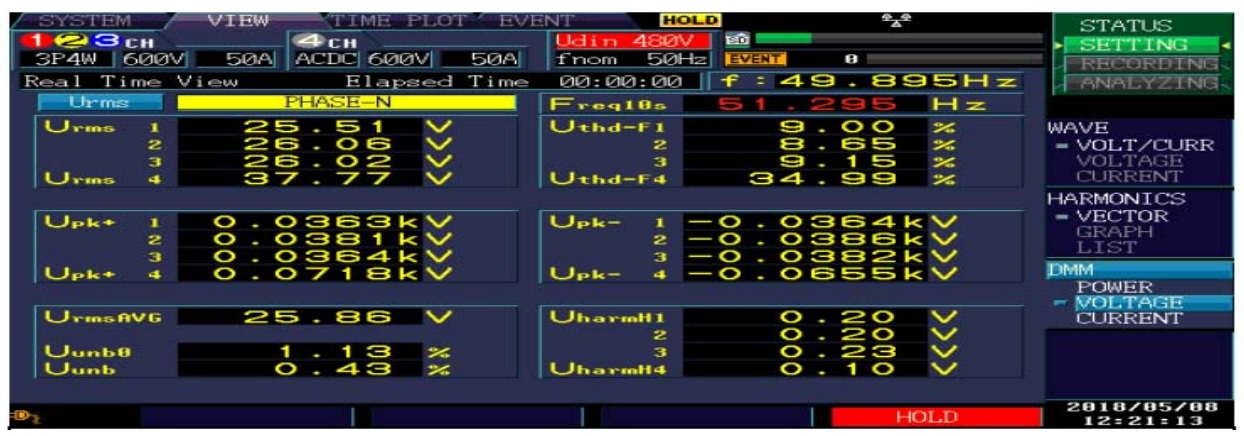

Fig. 48: Experimental results-DVR with SPWM for swell (50\%) Total Harmonic Distortion (THD)

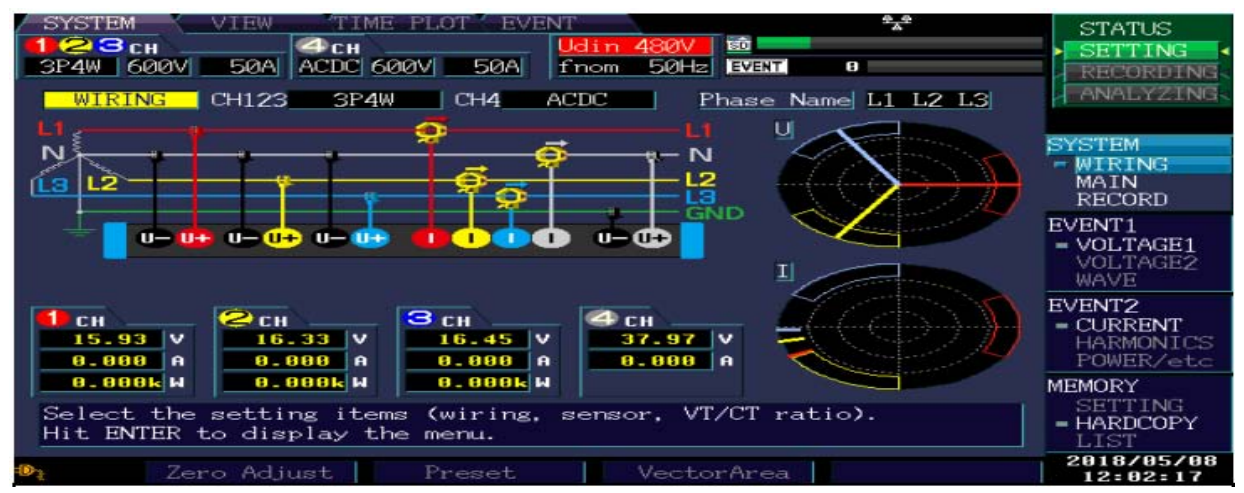

Fig. 49: Experimental results-DVR with SPWM for swell (50\%) voltage with compensation 
Table 5: Simulation results-sag

\begin{tabular}{lccrcc}
\hline Sag (\%) & $\begin{array}{c}\text { Source } \\
\text { voltage }\end{array}$ & $\begin{array}{c}\text { Source voltage } \\
\text { with sag }\end{array}$ & $\begin{array}{c}\text { Injected } \\
\text { voltage }\end{array}$ & $\begin{array}{c}\text { Load } \\
\text { voltage }\end{array}$ & THD \\
\hline Sag & & & & & \\
SPWM & & & & & \\
10 & 30 & 27.03 & 4.70 & 30.32 & 3.28 \\
25 & 30 & 22.51 & 9.02 & 30.58 & 5.86 \\
35 & 30 & 19.52 & 10.54 & 29.27 & 5.49 \\
50 & 30 & 22.51 & 9.02 & 30.58 & 4.15 \\
3H I SPWM & & & & \\
10 & 30 & 27.03 & 4.16 & 29.83 & 2.26 \\
25 & 30 & 22.51 & 8.35 & 30.01 & 2.18 \\
35 & 30 & 19.52 & 8.91 & 28.00 & 2.80 \\
50 & 30 & 22.51 & 8.35 & 30.01 & 4.12 \\
3H I PS SPWM & & & & \\
10 & 30 & 27.03 & 4.09 & 29.83 & 1.27 \\
25 & 30 & 22.51 & 8.48 & 30.29 & 2.24 \\
35 & 30 & 19.52 & 8.85 & 28.17 & 2.59 \\
50 & 30 & 22.51 & 8.47 & 30.29 & 3.79 \\
Experimental result & & & & \\
SPWM & & & & & \\
25 & 30 & 23.00 & 8.00 & 30.00 & 5.00 \\
36 & 30 & 19.00 & 12.00 & 29.00 & 5.34 \\
50 & 30 & 15.00 & 15.00 & 28.00 & 5.65 \\
\hline
\end{tabular}

Table 6: Simulation results-swell

\begin{tabular}{lccrcc}
\hline Sag (\%) & $\begin{array}{c}\text { Source } \\
\text { voltage }\end{array}$ & $\begin{array}{c}\text { Source voltage } \\
\text { with swell }\end{array}$ & $\begin{array}{c}\text { Injected } \\
\text { voltage }\end{array}$ & $\begin{array}{c}\text { Load } \\
\text { voltage }\end{array}$ & THD \\
\hline Swell & & & & & \\
SPWM & & & & & \\
10 & 30 & 33.04 & 4.98 & 28.89 & 2.74 \\
25 & 30 & 37.53 & 6.82 & 30.01 & 3.81 \\
35 & 30 & 40.53 & 12.32 & 28.50 & 3.21 \\
50 & 30 & 37.53 & 6.82 & 30.01 & 3.69 \\
3H I SPWM & 30 & 33.04 & 5.01 & 28.91 & 2.98 \\
10 & 30 & 36.77 & 7.56 & 30.59 & 2.42 \\
25 & 30 & 40.53 & 12.12 & 28.74 & 3.22 \\
35 & 30 & 37.62 & 7.55 & 30.59 & 3.76 \\
50 & 30 & 33.04 & 5.02 & 28.91 & 1.00 \\
3H I PS SPWM & 37.53 & 7.57 & 30.60 & 1.42 \\
10 & 30 & 30.53 & 12.13 & 28.74 & 2.71 \\
25 & 30 & & 7.57 & 30.60 & 3.22 \\
35 & 30 & 37.53 & & & \\
50 & 30 & 33.00 & 4.00 & 29.16 & 5.67 \\
Experimental result & & & & \\
SPWM & & 35.00 & 6.00 & 30.61 & 5.35 \\
10 & 30 & 41.00 & 12.00 & 30.22 & 5.30 \\
\hline 16 & 30 & & & & \\
36 & 30 & &
\end{tabular}

\section{CONCLUSION}

This study mainly discusses about the Power Quality (PQ) problems mitigation algorithm. The developed system is compared with existing system and is implemented by using MATLAB/Simulink algorithms. From the experimental results it is observed that, the proposed system produces accurate duration and depth of the Power Quality (PQ) problems. The proposed system is analyzed and calculated the fault for various different conditions, i.e., during fault condition in all phases and fault in individual phase and faulty condition with combinations of two phases. This study gives a complete analysis of multi-level DVR. Dynamic Voltage Restore (DVR) is considered as one of the most efficient custom power device for voltage sags and swells mitigation through simulation.

\section{REFERENCES}

Devadasu, G. and M. Sushama, 2017c. A multilevel diode clamped SVPWM based Interline dynamic voltage restorer with sag and swell limiting function. Intl. J. Electron. Eng. Res., 9: 751-760.

Devadasu, G. and M. Sushama, 2017a. Accurate detection of harmonics due to non linear loads in power system network using FFT analysis. Intl. J. Eng. Sci. Res. Technol., 6: 156-166.

Devadasu, G. and M. Sushama, 2017b. Harmonics identification using FFt and harmonics mitigation with unit vector based APF for the systems connected to BLDC drive. Intl. J. Electron. Eng. Res., 9: $281-292$.

Devadasu, G. and M. Sushama, 2017d. Modeling and design of a transformer less active voltage quality regulator with a novel DVR. Intl. J. Electron. Eng. Res., 9: 761-772.

Devadasu, G. and M. Sushama, 2018. A novel approach of inverter topology of DVR for mitigation of voltage sags and voltage swells. Intl. J. Appl. Eng. Res., 13: 12115-12123.

Devadasu, M.G. and D.M. Sushama, 2015. Comparative study of sag and swell mitigation by a novel multi level DVR with wavelets. Intl. J. Innovations Eng. Technol., 8: 48-54.

Li, Y.W., P.C. Loh, F. Blaabjerg and D.M. Vilathgamuwa, 2007. Investigation and improvement of transient response of DVR at medium voltage level. IEEE. Trans. Ind. Appl., 43: 1309-1319.

Mangalanathan, J., 2014. Hardware implementation of single phase dynamic voltage restorer in mitigating voltage sag and swell. Intl. J. Innovative Sci. Eng. Technol., 1: 187-193.

Mishra, S.P., B. Biswal, J.P. Roselyn and D. Devaraj, 2013. Simulation and analysis of DVR for mitigating voltage sags and swells. Procedia Eng., 64: $341-350$.

Roncero-Sanchez, P., E. Acha, J.E. Ortega-Calderon, V. Feliu and A. Garcia-Cerrada, 2009. A versatile control scheme for a dynamic voltage restorer for power-quality improvement. IEEE Trans. Power Delivery, 24: 277-284. 